\title{
Bowel preparation for colonoscopy: European Society of Gastrointestinal Endoscopy (ESGE) Guideline - Update 2019
}

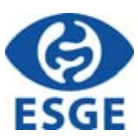

Authors

Cesare Hassan ${ }^{1}$, James East ${ }^{2}$, Franco Radaelli ${ }^{3}$, Cristiano Spada ${ }^{4}$, Robert Benamouzig ${ }^{5}$, Raf Bisschops ${ }^{6}$, Michael Bretthauer $^{7}$, E. Dekker ${ }^{8}$, Mario Dinis-Ribeiro ${ }^{9}$, Monika Ferlitsch ${ }^{10}$, Lorenzo Fuccio ${ }^{11}$, Halim Awadie ${ }^{12}$, Ian Gralnek ${ }^{12}$, Rodrigo Jover ${ }^{13}$, Michal F. Kaminski ${ }^{14}$, Maria Pellisé ${ }^{15}$, Konstantinos Triantafyllou ${ }^{16}$, Giuseppe Vanella ${ }^{17}$, Carolina Mangas-Sanjuan ${ }^{13}$, Leonardo Frazzoni ${ }^{11}$, Jeanin E. Van Hooft ${ }^{8}$, Jean-Marc Dumonceau ${ }^{18}$

Institutions

1 Digestive Endoscopy, Nuovo Regina Margherita Hospital, Rome, Italy

2 Translational Gastroenterology Unit, John Radcliffe Hospital, University of Oxford, and Oxford NIHR Biomedical Research Centre, Oxford, United Kingdom

3 Valduce Hospital, Como, Italy

4 Digestive Endoscopy Unit, Fondazione Poliambulanza, Brescia, Italy

5 Gastroenterology Unit, Bobigny, France

6 University Hospitals Leuven, KU Leuven, Department of Gastroenterology and Hepatology

7 Institute of Health and Society, University of Oslo Department of Transplantation Medicine, Oslo University Hospital, Norway

8 Department of Gastroenterology and Hepatology Amsterdam University Medical Centers, Amsterdam, The Netherlands

9 CIDES/CINTESIS, Faculty of Medicine, University of Porto, Porto, Portugal

10 Department of Internal Medicine III, Division of Gastroenterology \& Hepatology, Medical University of Vienna, Austria; Austrian Society of Gastroenterology and Hepatology (OEGGH): Quality Assurance Working Group, Austria

11 Gastroenterology Unit, Department of Medical and Surgical Sciences, S. Orsola-Malpighi Hospital, University of Bologna, Bologna, Italy

12 Institute of Gastroenterology and Hepatology Emek Medical Center Afula, Israel; Rappaport Faculty of Medicine, Technion-Israel Institute of Technology, Israel

13 Servicio de Medicina Digestiva. Hospital General Universitario de Alicante. Instituto de Investigación Sanitaria ISABIAL, Alicante, Spain

14 Department of Gastroenterology, Hepatology and Oncology, Center for Postgraduate Medical Education, Warsaw, Poland

15 Gastroenterology Department, Institut de Malalties Digestives i Metabòliques, Hospital Clínic, Institut
d'Investigacions Biomèdiques August Pi i Sunyer, (IDIBAPS), University of Barcelona, Barcelona, Spain

16 Hepatogastroenterology Unit, Second Department of Internal Medicine and Research Institute, Athens University, Athens Greece

17 Digestive Disease Unit, Sant'Andrea Hospital, Sapienza University of Rome, Italy

18 Gedyt Endoscopy Center, Buenos Aires, Argentina

Bibliography

DOI https://doi.org/10.1055/a-0959-0505

Published online: 11.7.2019 | Endoscopy 2019; 51: 775-794

(c) Georg Thieme Verlag KG Stuttgart · New York

ISSN 0013-726X

Corresponding author

Cesare Hassan, MD, Digestive Endoscopy, Nuovo Regina Margherita Hospital, Via E. Morosini 30, 00153 Roma, Italy cesareh@hotmail.com

丹 Supplementary material

Online content viewable at:

https://doi.org/10.1055/a-0959-0505

\section{MAIN RECOMMENDATIONS}

ESGE recommends a low fiber diet on the day preceding colonoscopy.

Strong recommendation, moderate quality evidence.

ESGE recommends the use of enhanced instructions for bowel preparation.

Strong recommendation, moderate quality evidence. ESGE suggests adding oral simethicone to bowel preparation.

Weak recommendation, moderate quality evidence.

ESGE recommends split-dose bowel preparation for elective colonoscopy.

Strong recommendation, high quality evidence.

ESGE recommends, for patients undergoing afternoon 
colonoscopy, a same-day bowel preparation as an acceptable alternative to split dosing.

Strong recommendation, high quality evidence.

ESGE recommends to start the last dose of bowel preparation within 5 hours of colonoscopy, and to complete it at least 2 hours before the beginning of the procedure.

Strong recommendation, moderate quality evidence.
ESGE recommends the use of high volume or low volume PEG-based regimens as well as that of non-PEG-based agents that have been clinically validated for routine bowel preparation. In patients at risk for hydroelectrolyte disturbances, the choice of laxative should be individualized. Strong recommendation, moderate quality evidence.

\section{SOURCE AND SCOPE}

This Guideline is an official statement of the European Society of Gastrointestinal Endoscopy (ESGE). It provides practical advice on the different aspects of bowel preparation for colonoscopy. The Grading of Recommendations Assessment, Development, and Evaluation (GRADE) system was adopted to define the strength of recommendations and the quality of evidence.

\section{Introduction}

Inadequate bowel preparation has a detrimental effect on all aspects of the colonoscopy procedure and, especially, on its accuracy. It has been associated with significantly lower rates of detection of adenomas and advanced adenomas in two recent meta-analyses [1,2]. A subsequent prospective observational study with repeat colonoscopy performed by a blinded endoscopist revealed a threefold higher miss rate for adenomas $\geq 5 \mathrm{~mm}$ in size when bowel cleansing was inadequate [3]. Inadequate bowel preparation is also one of the most unfavorable predictors for cecal intubation failure [4-6] and unsatisfactory patient experience [7]. In addition it results in shorter colonoscopy surveillance intervals $[8,9]$, longer hospital stays, and increased healthcare costs $[10,11]$ and may render screening colonoscopy cost-ineffective [12]. For these reasons, a $\geq 90 \%$ minimum standard for adequate bowel preparation (assessed using validated scales) has been recently recommended by the Quality Committee of the European Society of Gastrointestinal Endoscopy (ESGE) [13].

Since the publication of the ESGE Guideline on bowel preparation in 2013 [14], additional evidence has been published on the efficacy and safety of different aspects of bowel preparation, including diet, timing, and type of laxative, as well as patient information and specific scenarios. The main aim of this update is to incorporate such new evidence into the clinical recommendations to be adopted in routine and specific scenarios.

\section{Methods}

The Guideline Committee chairs worked with subgroup leaders (C.H., J.E, J.-M.D., C.S., F.R.) to identify pertinent systematic search terms that included "colon," "rectum," "bowel preparation," "diet," "laxative," "colonoscopy," and "endoscopy." Searches were performed (at least) on Medline (via PubMed) and the Cochrane Central Register of Controlled Trials from after 2013 (date of the previous ESGE guideline [14]) up to December 2018. Evidence tables were generated for each key question (Appendix 1s, online-only Supplementary Material), summarizing the level of evidence from the available studies. For important outcomes, articles were individually assessed using the Grading of Recommendations Assessment, Development, and Evaluation (GRADE) system to grade the evidence levels and recommendation strengths (see Appendix 2s) [15]. The role of bowel preparation as a metric of the quality of colonoscopy was excluded as this had already been addressed in the ESGE Quality Improvement Initiative [13]. The evidence tables are presented in Appendix 3s.

The subgroups developed draft proposals that were presented to the entire group for general discussion during a meeting held in January 2019 in Munich. Further details on the development methodology of ESGE guidelines have been reported elsewhere [16]. In March 2019, a draft prepared by the task force leaders was sent to all group members. After the agreement of

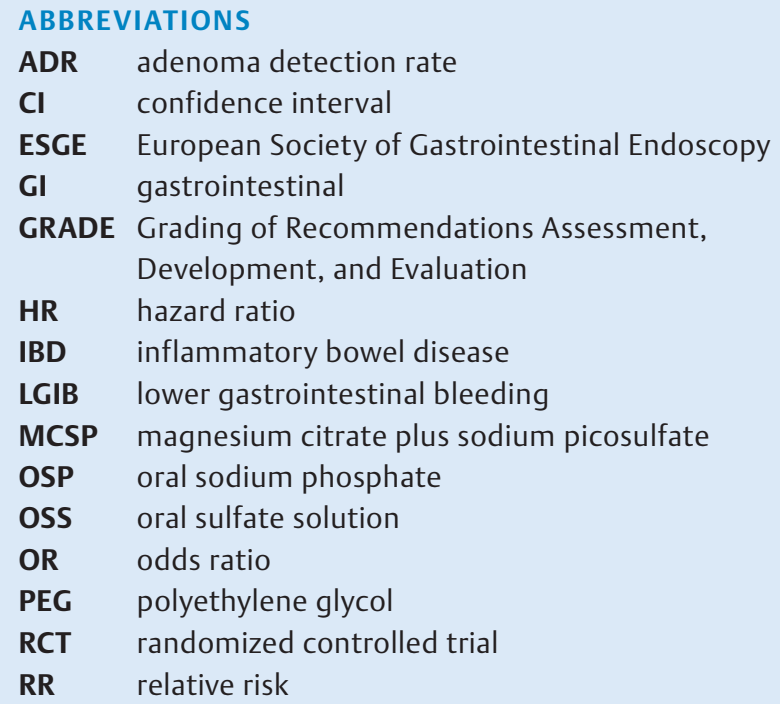


all group members had been obtained, the manuscript was sent for further comments to the ESGE national societies and individual members. After this it was submitted to the journal Endoscopy for publication.

This Guideline was issued in 2019 and will be considered for update in 2024. Any interim updates will be noted on the ESGE website: http://www.esge.com/esge-guidelines.html.

\section{Diet, and patient information}

RECOMMENDATION

ESGE recommends a low fiber diet on the day preceding colonoscopy.

Strong recommendation, moderate quality evidence.

Diet restriction, either a clear liquid diet or a low residue diet, has traditionally been recommended before colonoscopy but adherence is low. In a real-life prospective study (789 patients), the proportion of patients actually following a low residue diet for 2 days before colonoscopy was $44.2 \%$ and a high residue diet was independently associated with inadequate bowel preparation [17]. In trials, adherence to a low residue diet was $90.4 \%$ (874 of 967 patients randomized to a low residue diet) [18-23]. Two meta-analyses [24, 25] have compared a low residue diet vs. a clear liquid diet on the day before colonoscopy, with the same laxative in both arms. In the included trials, a diet was usually considered to be low residue when the total fiber intake was $<10 \mathrm{~g} /$ day. Most of the randomized controlled trials (RCTs) used the terms low residue/low fiber interchangeably and few of them specified the amount of fiber in their regimen. Examples of foods allowed in a low residue diet included some fresh peeled and pitted fruits and cooked vegetables (e.g., apples, carrots), cheese, meat, fish, and white bread, while wholegrain bread, muesli, brown rice were not allowed together with some fruits and vegetables (e.g., orange, mushroom). Some trials used prepackaged low fiber or fiberfree food while in others instructions were given to the participants on preparation of their food.

The first meta-analysis (9 RCTs, 1686 participants) found that, compared with a clear liquid diet, a low residue diet was associated with a higher willingness to repeat bowel preparation (odds ratio [OR] 1.86, 95\% confidence interval [Cl] $1.34-2.59 ; P<0.01)$ and better tolerability (OR 1.92, $95 \% \mathrm{Cl}$ $1.36-2.70 ; P<0.01)$ [24]. No differences between groups were found in terms of adequate bowel preparation (OR 1.21, $95 \% \mathrm{Cl} 0.64-2.28 ; P=0.58$ ) or adverse effects (OR $0.88,95 \% \mathrm{Cl}$ $0.58-1.35 ; P=0.57)$.

The most recent meta-analysis (12 RCTs, 3674 participants) grouped patients taking a low residue diet (8 RCTs) or a regular diet (4 RCTs) and compared them to patients taking a clear liquid diet [25]. The low residue diet was provided until breakfast $(n=1)$, lunch $(n=3)$, or dinner $(n=4)$, depending on study protocol. Compared with a clear liquid diet, the low residue/regular diet was associated with higher willingness to repeat the procedure (relative risk [RR] 1.08, $95 \% \mathrm{Cl} 1.01-1.16$ ), better toler- ability (RR 1.04, $95 \% \mathrm{Cl} 1.01-1.08$ ), and more frequent consumption of a targeted amount of the bowel laxative (RR $1.04,95 \% \mathrm{Cl} 1.01-1.08)$. No differences between groups were found in terms of adequate bowel preparation for the whole meta-analysis (RR 1.00, $95 \% \mathrm{Cl} 0.97-1.04$ ) as well as for subgroup analyses of high quality trials (5 RCTs, 1649 patients), split/morning preparations (5 RCTs, 1431 patients), or singledose preparation (4 RCTs, 1528 patients). No differences between groups were found in terms of adenoma detection rate (ADR) (3 RCTs, 1228 participants) or adverse events except for more hunger in the clear liquid diet arm (RR $1.93,95 \% \mathrm{Cl}$ $1.13-3.3)$.

A third meta-analysis (7 RCTs, 1590 participants) had similar inclusion criteria except that it did not restrict inclusion to studies with an identical purgative in both arms [26]. Compared with a clear liquid diet, a low residue diet was associated with higher willingness to repeat the procedure (RR $1.17,95 \% \mathrm{Cl}$ $1.09-1.26$ ) and better tolerance (RR 1.06, 95\%Cl 1.02-1.11). No differences between groups were found in terms of adequate bowel preparation (RR 1.01, $95 \% \mathrm{Cl} 0.91-1.13$ ), adverse events, and compliance with diet (RR $0.97,95 \% \mathrm{Cl} 0.87-1.08$ ).

A further four recent RCTs have also shown that patient satisfaction, ease of preparation, and willingness to repeat an identical preparation were higher with a low residue diet vs. a clear liquid diet in all trials that analyzed those outcomes (3, 2, and 1 RCTs, respectively); and the proportions of patients with adequate bowel preparation (3 RCTs) were similar or higher with a low residue diet vs. a clear liquid diet (Table 1s, Appendix 3s, online-only Supplementary Material) $[18,19,27,28]$. Recently, a possible additional effect of multiple-day vs. singleday low residue diet among participants receiving a split-dose bowel preparation has been excluded in a randomized trial [29].

Three RCTs assessed the effect of different liquids for bowel preparation with polyethylene glycol (PEG) [30-32]. One of these used dilution of PEG powder in Coca Cola Zero instead of water [30], and in another orange juice was kept in the mouth for a few seconds just before drinking the bowel preparation solution [32]. Various parameters were improved, including palatability of the bowel preparation (in both RCTs), speed of bowel preparation intake, bowel cleanliness, willingness to repeat the same preparation, and adverse events (mainly nausea) (in one RCT each). The third RCT found that the addition of $1 \mathrm{~L}$ of pineapple juice after bowel preparation intake had little effect (better proximal colon cleanliness but not in the whole coIon) [31]. Polyp and adenoma detection rates were not modified by these interventions.

Gum chewing was tested in three RCTs that used different protocols of gum chewing [33-35]. One of them used a purgative rarely employed for bowel preparation and reported belowstandard cecal intubation rates [33]. The other two RCTs reported higher patient satisfaction and willingness to repeat the same bowel preparation, more complete and faster bowel preparation intake, and less abdominal discomfort (one RCT each) but no improvement in bowel cleansing [34,35]. 


\section{RECOMMENDATION}

ESGE recommends the use of enhanced instructions for bowel preparation.

Strong recommendation, moderate quality evidence.

A meta-analysis (8 RCTs, 3795 patients) found that, compared with patients receiving regular instructions before colonoscopy, those who received enhanced instructions had better bowel cleanliness (OR 2.35, $95 \% \mathrm{Cl} 1.65-3.35$; $P<0.001$ ), a higher cecal intubation rate (OR 2.77, $95 \% \mathrm{Cl} 1.73-4.42$; $P<0.001)$ and more willingness to repeat the preparation (OR $1.91,95 \% \mathrm{Cl} 1.20-3.04 ; P=0.006)$, but a similar polyp detection rate [36]. Enhanced instructions consisted of visual aids, a social media app, telephone or short message service (SMS), and smartphone applications. Improvements were observed with $2 \mathrm{~L}$ as well as $4 \mathrm{~L}$ PEG and with split-dose as well as single-dose regimens, and with a delay between enhanced instructions and colonoscopy of 1 week or less as well as with a delay of more than 1 week. Adverse events were similar in both groups.

These data were confirmed in three more recent RCTs that used a phone call, a series of SMSs or a video as enhanced instructions for bowel preparation: compared to regular instructions, these improved bowel cleansing and ADR (three RCTs), and cecal intubation rate, and patient satisfaction (one RCT each) [37-39] (Table 2s). Interestingly, in the study that used SMSs, each patient received a total of 15 nonpersonalized messages and $89 \%$ of them reported that they would use SMS guidance again for their next colonoscopy. Finally, an RCT (283 patients) that used different types of bowel preparation found that sending a video before colonoscopy improved bowel cleanliness with low volume bowel preparations (2 L PEG glycol/ascorbate or sodium picosulfate/magnesium citrate) but not with 4 L PEG [40].

\section{Adjunctive drugs}

\section{RECOMMENDATION}

ESGE does not suggest the routine use of prokinetic agents for bowel preparation.

Weak recommendation, low quality evidence.

RCTs that compared identical bowel preparation regimens with vs. without prokinetics are summarized in Table 3s.

The effect of $24-96 \mu$ g lubiprostone, a chloride channel-2 activator increasing intestinal secretion and transit, has been assessed in three RCTs; all of them used single-dose bowel preparation [41-43]. The three RCTs reported better bowel cleansing with lubiprostone but the difference was significant in only one study [41]; this was the largest study and the only one to use low dose (2L) PEG. These results need to be confirmed by other studies using split regimens.
Itopride $(200 \mathrm{mg})$ improved bowel cleanliness in an RCT that used split-dose bowel preparation, with similar ADRs and adverse event rates between groups [44]. Finally, mosapride, a drug that is not as widely available as other prokinetics, has been tested in two RCTs with a single-dose bowel preparation; bowel cleansing was better in one study, in the left colon only [45].

Prokinetics have also been used in attempts to reduce the dose of purgative but the data do not allow conclusions to be drawn $[46,47]$.

\section{RECOMMENDATION}

ESGE suggests adding oral simethicone to bowel preparation.

Weak recommendation, moderate quality evidence.

A meta-analysis published in 2011 (7 RCTs, 714 patients) concluded that the amount of bubbles was less frequently unacceptable in patients who had received oral simethicone vs. those who had not, but no difference in colon cleanliness was found and the diagnostic yield was not reported [48].

Since then, four RCTs (see Table 4s) have compared identical bowel preparation regimens with vs. without oral simethicone; they found that oral simethicone decreases the amount of bubbles (four RCTs), improves bowel cleanliness (three RCTs), and also the ADR (two RCTs). Adverse events were analyzed in only three RCTs; two found that they were less frequent with vs. without simethicone. A meta-analysis assessed these four RCTs (1536 patients); in a subgroup analysis it found that oral simethicone increases the ADR (OR 1.23, 95\% Cl 1.04-1.47, $P=$ 0.02 ) [49]. Of note, the doses of simethicone used in these four RCTs were higher than those used in previous RCTs (400$1200 \mathrm{mg}$ vs. $<400 \mathrm{mg}$ in 6 of 7 RCTs included in the 2011 metaanalysis) [48]. No other antifoaming agent has been recently studied for colonoscopy.

Another meta-analysis is difficult to interpret as it included studies using different purgatives in the arm with vs. without simethicone [50].

Various professional societies, including ESGE, as well as endoscope manufacturers, have warned against the use of simethicone through the auxiliary water channel during endoscopy $[51,52]$. If it is used during endoscopy, simethicone should be injected via the biopsy rather than the auxiliary water channel of the endoscope, at the lowest effective concentration. Simethicone residues could contribute to the formation of biofilms and the biopsy channel is brushed during reprocessing while the auxiliary water channel is not.

\section{RECOMMENDATION}

ESGE recommends against the routine use of enemas for bowel preparation.

Strong recommendation, moderate quality evidence. 
An RCT found that adding an enema to standard bowel preparation did not improve bowel cleansing and decreased the acceptability of bowel preparation [53]. Another RCT found that a 5 -day regimen of oral nutritional supplements plus enema did not provide adequate bowel cleansing [54].

\section{Timing}

\section{RECOMMENDATION}

ESGE recommends split-dose bowel preparation for elective colonoscopy.

Strong recommendation, high quality evidence.

A meta-analysis (47 RCTs, 13478 patients) found that splitdose regimens, regardless of the type and dose of the cleansing agent, provided excellent/good colon cleansing more frequently than day-before bowel preparation (OR 2.51, 95\% CI 1.863.39). This result was confirmed in subanalyses restricted to PEG (OR 2.60, 95\% Cl 1.46-4.63), sodium phosphate (OR $9.34,95 \% \mathrm{Cl} 2.12-41.11$ ), and picosulfate (OR 3.54, $95 \% \mathrm{Cl}$ $1.95-6.45)$. Moreover, split dosing was associated with a higher proportion of patients willing to repeat the preparation (OR $1.90,95 \% \mathrm{Cl} 1.05-3.46$ ) [55].

Seven subsequent RCTs comparing identical cleansing agents (sodium picosulfate, three studies [56-58]; high volume PEG, two studies [59,60]; low volume PEG, two studies $[61,62])$ further confirmed the superiority of split dosing over a day-before regimen in terms of colon cleansing [56-62] and patient tolerability [59-61] (Table 5s).

Concerning the detection of neoplastic lesions, the abovementioned meta-analysis [55] included two small trials that reported on this outcome, and no difference was found. Two further RCTs were specifically designed and adequately powered to compare split-dose vs. single-dose regimens regarding the detection of neoplastic lesions. In one RCT that included 690 patients undergoing screening colonoscopy after positive fecal immunochemical testing, split-dose vs. day-before bowel preparation with $2 \mathrm{~L}$ PEG/ascorbate resulted in a higher detection rate of adenomas (primary study endpoint; $53.0 \%$ vs. $40.9 \%$; RR 1.22, $95 \% \mathrm{Cl} 1.03-1.46$; number needed to treat [NNT] =9) and of advanced adenomas ( $26.4 \%$ vs. $20.0 \%$; RR $1.35,95 \% \mathrm{Cl}$ $1.06-1.73$; NNT = 16) [62]. The other RCT compared split-dose $2 \mathrm{~L}$ PEG/ascorbate vs. a day-before regimen of sodium picosulfate/magnesium citrate; the split regimen was associated with a trend towards a higher polyp detection rate (primary endpoint; $51.5 \%$ vs. $44.0 \%, P=0.14$ ), and a significantly higher detection rate of right-sided polyps ( $28.0 \%$ vs. $16.6 \%, P=0.007$ ) and adenomas (21.0\% vs. $11.9 \%, P=0.015)$ [63]. Moreover, large observational studies confirmed that split dosing led to higher polyp and/or adenoma detection rates compared with single-dose regimens [64-66].
RECOMMENDATION

ESGE recommends, for patients undergoing afternoon colonoscopy, a same-day bowel preparation as an acceptable alternative to split dosing.

Strong recommendation, high quality evidence.

Two meta-analyses (11 and 14 RCTs) compared split-dose with same-day bowel preparation and showed similar results regarding the quality of bowel preparation, patient willingness to repeat it, and the overall tolerability $[67,68]$, albeit patients taking the same-day regimen reported less bloating (OR 0.68, $95 \% \mathrm{Cl} 0.40-0.94$ ) [67] and better sleep quality (OR 0.44 , $95 \% \mathrm{Cl} 0.24-0.82$ ) [68]. The ADR was similar for the two regimens [67]. It is noteworthy that most patients included in these studies were scheduled in afternoon colonoscopy slots.

Three RCTs compared same-day vs. split regimens for morning colonoscopy only, using an identical PEG bowel preparation [69-71]. The same-day regimen was associated with a significantly lower quality of bowel preparation in one study [69], whereas the other two studies reported similar efficacy in bowel cleansing but lower patient tolerability and compliance [70, 71], and lower willingness to repeat the same preparation in the future [70]. Overall, these data favor split-dose over sameday regimens for morning colonoscopy (Table 6s).

\section{RECOMMENDATION}

ESGE recommends to start the last dose of bowel preparation within 5 hours of colonoscopy, and to complete it at least 2 hours before the beginning of the procedure. Strong recommendation, moderate quality evidence.

Observational studies have shown an inverse correlation between the degree of mucosal cleanliness and the interval between the last dose of bowel preparation and the start of colonoscopy $[72,73]$; an interval of $3-5$ hours resulted in the best preparation quality scores throughout the colon [73]. A metaregression analysis of 29 RCTs comparing split vs. day-before regimens showed that the clinical gain of the split-dose regimen was highest within 3 hours from last dose intake, progressively decreased after 4 to 5 hours, and became statistically not significant at 5 hours [74].

Some clinicians, mainly anesthesiologists, are concerned about the risk of pulmonary aspiration of residual gastric fluid when a second dose of bowel preparation is given close to the time of endoscopy.

However, a systematic review, including 28 RCTs, 2 controlled trials, and 10 observational studies (22 936 patients) did not show any association between shorter "nothing per mouth" intervals prior to colonoscopy and pulmonary aspiration risk [75].

In addition, several endoscopic studies demonstrated that the residual gastric volumes in patients who had a split-dose regimen were similar to [76-79] or even lower [80] than those 
obtained by more prolonged fasting after a day-before regimen. This supports the notion that bowel preparation regimens should be regulated in the same way as clear liquids. Thus, it is reasonable and safe to recommend 2 hours as the minimum interval between the intake of last dose of preparation and the colonoscopy, in line with the American Society of Anesthesiologists' recommendation for clear liquids (e.g., water, fruit juice without pulp, carbonated beverages, clear tea, and black coffee) before elective procedures requiring sedation/analgesia or anesthesia [81].

\section{Laxatives}

\section{RECOMMENDATION}

ESGE recommends the use of high volume or low volume PEG-based regimens as well as that of non-PEG-based agents that have been clinically validated for routine bowel preparation. In patients at risk for hydroelectrolyte disturbances, the choice of laxative should be individualized.

Strong recommendation, moderate quality evidence.

Data on the efficacy and safety of laxatives formally validated in a clinical setting are provided in $>$ Table 1 .

\section{High volume PEG}

Efficacy

In a recent meta-analysis, split-dose high volume ( $\geq 3 \mathrm{~L})$ appeared to be superior to split-dose low volume PEG (6 studies; 1305 patients; OR 1.89, $95 \% \mathrm{Cl} 1.01-3.46$ ) [82]. This confirmed a previous meta-analysis [83] showing the superiority of split-dose high volume PEG vs. other alternatives (9 studies; 2477 patients; OR $3.46,95 \% \mathrm{Cl} 2.45-4.89$ ) including low volume PEG with different adjuvants and sodium phosphate, regardless of the adoption of the split regimen. After the metaanalyses were published, several trials compared high volume PEG vs. low volume PEG or non-PEG split regimens as detailed in each of the sections below. Overall, such trials showed an equivalence or superiority of the high volume vs. low volume PEG or non-PEG regimens in terms of efficacy, while confirming the worse tolerability of the high volume PEG regimens.

\section{Safety}

High volume osmotically balanced solutions containing PEG and electrolytes are intended to impair the intestinal absorption of water and sodium. This is achieved by maintaining isosmosis of the bowel lumen content. Studies have not demonstrated significant alterations in vital or biochemical parameters (e.g., sodium, potassium, chloride, bicarbonates) linked to these formulations. This accounts for the high safety and few contraindications associated with these products, which are also considered safe in the setting of renal failure, pre-existing electrolyte imbalance, or in those who cannot tolerate sodium loads (e.g., patients with cirrhosis) [84,85].

\section{Low volume PEG plus adjuvants}

Efficacy

\section{L PEG plus ascorbate ( $\triangleright$ Table 1, Table 7s)}

In order to reduce the volume of PEG solutions, with the aim of improving tolerability, a formulation of 2 L PEG with the adjunct of osmotically active ascorbic acid has been introduced. One meta-analysis [86], including 11 RCTs comparing 2 L PEG plus ascorbate vs. 4-L PEG preparations for elective colonoscopies, has shown a noninferior efficacy for bowel cleansing (OR $1.08,95 \% \mathrm{Cl} 0.98-1.28)$ but a significantly better compliance for 2 L PEG plus ascorbate (OR 2.23, 95\%Cl 1.67-2.98), with reduced nausea and vomiting. Initial reports questioned the ability of the product to provide a satisfactory cleansing in the right colon [87], but more recent RCTs have reported a similar efficacy of colon cleansing also in this clinically important segment [88-91].

Four additional trials published after the abovementioned meta-analysis have compared $2 \mathrm{~L}$ PEG plus ascorbate vs. $4 \mathrm{~L}$ PEG $[60,89,92,93]$. One of these included only afternoon colonoscopies [92] and demonstrated a trend for the $4 \mathrm{~L}$ PEG to provide better colon cleansing than 2 L PEG plus ascorbate (both administered in a same-day regimen), but no difference was noticed in overall cleansing adequacy and patient satisfaction (despite higher bloating in the PEG plus ascorbate regimen). In the other three published RCTs $[60,89,93]$ comparing splitdose 2 L PEG plus ascorbate with split-dose $4 \mathrm{~L}$ PEG, successful cleansing was very high (between 92.1\% [60] and 97.5\% [89]) and not different between the two products (two studies also demonstrated similarly high ADRs $[89,93]$ ); moreover, differently from previous studies, no difference was demonstrated in the adequacy of right colon cleansing. As previously demonstrated, 2 L PEG plus ascorbate solutions were associated with higher tolerability and willingness to repeat the regimen.

Four RCTs have compared 2 L PEG plus ascorbate vs. magnesium citrate plus sodium picosulfate (MCSP) [94-97]. The most recent of these [95], with both preparations in split-dose regimens, demonstrated similarly high overall cleansing success (93.5\% vs. $93.8 \%, P=0.72$; including successful cleansing of the right colon), polyp detection rates, and ADRs, along with a higher rate of adverse events (mainly nausea) in the PEG plus ascorbate group and a higher willingness to repeat the regimen in the MCSP group (83.4\% vs. 92.1, $P=0.001)$. Another RCT involving 973 patients [96] and comparing 2 L PEG plus ascorbate vs. MCSP and vs. 4L PEG found no difference in bowel cleansing between products, provided they were used in split-dose regimens, but MCSP $(\mathrm{OR}=8.39$ [95\%Cl 5.74-12.27]) and $2 \mathrm{~L}$ PEG ascorbate $(\mathrm{OR}=1.69[95 \% \mathrm{Cl} 1.21-2.35])$ were better tolerated than $4 \mathrm{~L}$ PEG.

After the abovementioned meta-analysis had been published, two RCTs compared 2 L PEG plus ascorbate vs. oral sodium phosphate (OSP) $[98,99]$. In one [98], the two products were equivalent in cleansing efficacy, but PEG plus ascorbate was associated with less vomiting and more complaining about the volume and inability to complete the regimen. In the other RCT [99], in contrast, 2 L PEG plus ascorbate was associated with higher efficacy of bowel cleansing $(93.4 \%$ vs. $22.8 \%$, 
- Table 1 Summary data on efficacy and safety of validated laxatives for routine bowel preparation.

\begin{tabular}{|c|c|c|}
\hline Agent & Efficacy (split/same-day regimen) & Safety \\
\hline $\begin{array}{l}\text { High volume polyethylene } \\
\text { glycol (PEG) }\end{array}$ & $\begin{array}{l}\text { Noninferior or superior to low volume PEG or } \\
\text { non-PEG regimens }\end{array}$ & $\begin{array}{l}\text { Not recommended in: } \\
\text { - Patients with congestive cardiac failure (NYHA class III or IV). }\end{array}$ \\
\hline \multicolumn{3}{|c|}{ Low volume PEG plus adjuvants } \\
\hline . 2 L PEG + ascorbate & $\begin{array}{l}\text { Noninferior to high volume PEG and non-PEG } \\
\text { regimens }\end{array}$ & $\begin{array}{l}\text { Not recommended in patients with: } \\
\text { - Severe renal insufficiency (creatinine clearance }<30 \mathrm{~mL} / \mathrm{min} \text { ); } \\
\text { - Congestive heart failure (NYHA III or IV); } \\
\text { - Phenylketonuria; or } \\
\text { - Glucose-6-phosphate dehydrogenase deficiency. }\end{array}$ \\
\hline - 2 L PEG + citrate & $\begin{array}{l}\text { Noninferior to high volume PEG or } 2 \text { L PEG + } \\
\text { ascorbate }\end{array}$ & $\begin{array}{l}\text { Not recommended in patients with: } \\
\text { - Severe renal insufficiency (creatinine clearance }<30 \mathrm{~mL} / \mathrm{min} \text { ): } \\
\text { - Congestive heart failure (NYHA III or IV) } \\
\text { - Unstable angina; or } \\
\text { - Acute myocardial infarction. } \\
\text { No long-term data available. } \\
\text { Limited post-marketing data available. }\end{array}$ \\
\hline - 1 L PEG + ascorbate & $\begin{array}{l}\text { Noninferior to } 2 \text { L PEG + ascorbate, oral sulfate } \\
\text { solution (OSS), and magnesium citrate plus } \\
\text { picosulphate (MCSP). } \\
\text { No comparison with high volume PEG. }\end{array}$ & $\begin{array}{l}\text { Not recommended in patients with: } \\
\text { " Severe renal insufficiency (creatinine clearance }<30 \mathrm{~mL} / \mathrm{min} \text { ); } \\
\text { " Congestive heart failure (NYHA III or IV); } \\
\text { " Phenylketonuria; or } \\
\text { - Glucose-6-phosphate dehydrogenase deficiency. } \\
\text { Adequate hydration must be maintained. } \\
\text { Limited post-marketing data available. }\end{array}$ \\
\hline - 2 L PEG + bisacodyl & $\begin{array}{l}\text { Noninferior to high volume PEG or } 2 \text { L PEG + } \\
\text { ascorbate }\end{array}$ & $\begin{array}{l}\text { Occasional reports of ischemic colitis with high dose bisacodyl. } \\
\text { Not recommended in: } \\
\text { - Patients with congestive cardiac failure (NYHA class III or IV). }\end{array}$ \\
\hline $\begin{array}{l}\text { Magnesium citrate plus } \\
\text { picosulphate (MCSP) }\end{array}$ & $\begin{array}{l}\text { Noninferior to high volume PEG or } 2 \text { L PEG + } \\
\text { ascorbate }\end{array}$ & $\begin{array}{l}\text { Not recommended in patients with: } \\
\text { - Congestive heart disease; } \\
\text { " Hypermagnesemia; or } \\
\text { - Severe kidney insufficiency. } \\
\text { Not recommended in patients at risk for: } \\
\text { - Hypermagnesemia; or } \\
\text { - Rhabdomyolysis. }\end{array}$ \\
\hline $\begin{array}{l}\text { Trisulfate (magnesium } \\
\text { sulfate, sodium sulfate, } \\
\text { and potassium sulfate), } \\
\text { also called oral sulfate } \\
\text { solution (OSS) }\end{array}$ & $\begin{array}{l}\text { Noninferior to high volume PEG, } 2 \text { L PEG as- } \\
\text { corbate } \\
\text { Superior to MCSP in a single RCT }\end{array}$ & $\begin{array}{l}\text { Not recommended in patients with: } \\
\text { - Severe renal insufficiency (creatinine clearance }<30 \mathrm{~mL} / \mathrm{min} \text { ); } \\
\text { " Congestive heart failure; or } \\
\text { - Ascites. }\end{array}$ \\
\hline
\end{tabular}

$P<0.001$; also in the right colon), significantly higher willingness to repeat bowel preparation $(88.4 \%$ vs. $78.1 \%, P<$ $0.001)$, and fewer electrolyte disturbances; however in this last trial PEG plus ascorbate was administered in split-dose fashion, while OSP was administered as a day-before bowel preparation.

\section{L PEG plus citrate ( $\triangleright$ Table 1 )}

More recently, a new formulation of $2 \mathrm{~L}$ PEG plus citrate and simethicone has become available. When this solution has been compared (in RCTs) with $4 \mathrm{~L}$ PEG, there was no difference in adequate bowel cleansing $(73.6 \%$ vs. $72.3 \%, 95 \% \mathrm{Cl}$ difference -7.5 to 10.1 ), safety, and compliance, but gastrointestinal tolerability was better for the low volume solution ( $25.4 \%$ vs. 37.0 $\%, P<0.01)$ and acceptability was higher (93.9\% vs. $82.2 \%, P<$ $0.001)$ [100]. Moreover, when compared with 2 L PEG plus as- corbate, bowel cleansing ( $78.3 \%$ vs. $74.3 \%, P=0.37$ ), safety (including electrolyte measurement), acceptability (81.4\% vs. $80.8 \%, P=0.74)$, compliance, and willingness to repeat the same preparation were equivalent [101]. In both studies, the rates of adequate colon preparation were higher for all the products when administered according to the split-dose modality. Adenoma and polyp detection rates were not evaluated.

\section{L PEG plus ascorbate ( $\triangleright$ Table 1 )}

A new $1 \mathrm{~L}$ PEG solution with a higher ascorbate concentration has been evaluated against MCSP, oral sulfate solution (OSS), and 2 L PEG plus ascorbate in three RCTs. These included patients aged between 18 and 85 , with blinded central readers evaluating primary endpoints using validated scales.

Compared with MCSP, with both products taken in a day-before fashion [102], 1 L PEG plus ascorbate demonstrated nonin- 
ferior overall cleansing (62.0\% vs. $53.8 \% ; P=0.04)$ and high quality cleansing in the right colon $(4.4 \%$ vs. $1.2 \% ; P=0.03)$ in the intention-to-treat analysis (and superiority in the perprotocol analysis), along with noninferior polyp and adenoma detection rates. Tolerability and adherence were high (but the latter was higher with MCSP), despite a higher rate of mild adverse events in the 1 I PEG plus ascorbate group (17.0\% vs. $10.0 \% ; P=0.03)$.

When compared with OSS in a split-dose schedule [103] $1 \mathrm{~L}$ PEG plus ascorbate was noninferior in terms of successful bowel cleansing ( $85.1 \%$ vs. $85.0 \% ; P=0.53$ ) and high quality cleansing of the right colon ( $35.9 \%$ vs. $29.3 \%$; $P=0.06$ ). No difference was demonstrated in polyp and adenoma detection rates, adherence, overall tolerability and safety.

Finally, when $1 \mathrm{~L}$ PEG plus ascorbate in split-dose and sameday fashion was compared with split-dose 2 L PEG plus ascorbate [104], noninferiority of 1 L PEG plus ascorbate in both regimens was established in the intention-to-treat analysis. Furthermore, superiority was demonstrated in the per-protocol analysis of overall success of split-dose $1 \mathrm{~L}$ PEG plus ascorbate (97.3\% vs. $92.2 \% ; P=0.01$ ) and of high quality right colon cleansing for both split-dose and same-day $1 \mathrm{~L}$ PEG plus ascorbate regimens vs. 2 L PEG plus ascorbate. Polyp and adenoma detection rates were also noninferior. Adherence, tolerability, and safety (including blood and urinary values) were comparable between arms, despite a higher rate of vomiting in the same-day regimen arm compared with the split-dose 2 L PEG ascorbate regimen $(6.3 \%$ vs. $1.1 \%, P=0.002)$.

\section{L PEG plus bisacodyl ( Table 1, Table 8s)}

One meta-analysis [105] of 6 RCTs found that, compared with 4 L PEG, 2 L PEG plus bisacodyl $(10-20 \mathrm{mg})$ provided similar bowel cleansing with no difference in abdominal pain, but was associated with less nausea, vomiting, and bloating.

After this meta-analysis was published, seven RCTs evaluated the addition of bisacodyl to PEG [88,106-111] compared with $4 \mathrm{~L}$ PEG and $2 \mathrm{~L}$ PEG plus ascorbate. Two RCTs further evaluated whether the addition of bisacodyl could lower the required volume of PEG plus ascorbate to $1 \mathrm{~L}[88,111]$, using $2 \mathrm{~L}$ PEG plus ascorbate as comparator. Three RCTs $[106,107,109]$ evaluated the addition of bisacodyl to PEG plus citrate plus simethicone.

All these trials, except one [106], demonstrated no substantial difference in overall colon cleansing, but improved tolerability only in RCTs using higher volumes of PEG as comparator. No difference was demonstrated in head-to-head comparison of split-dose 2 L PEG plus ascorbate with split-dose 2 L PEG plus bisacodyl [108]).

\section{Safety}

Solutions containing aspartame and ascorbate (such as $2 \mathrm{~L}$ and $1 \mathrm{~L}$ PEG plus ascorbate solutions) are contraindicated in patients with phenylketonuria or glucose-6-phosphate dehydrogenase deficiency [112]. These products are not recommended in patients with renal insufficiency and creatinine clearance $<30 \mathrm{~mL} / \mathrm{min}$ and in patients with New York Heart Association (NYHA) III or IV congestive heart failure. A high rate of hypernatremia has been observed following the administration of
$1 \mathrm{~L}$ PEG plus ascorbate, primarily due to the sodium content of the product. For this reason, additional clear liquids are recommended. Hyponatremia cases have been described with 2 L PEG ascorbate; this prompted caution in patients at risk of electrolyte disturbances.

In solutions where PEG is associated with citrate and simethicone, caution is suggested if the products are administered in patients with creatinine clearance $<30 \mathrm{~mL} / \mathrm{min}$, NYHA III or IV congestive heart failure, unstable angina, or acute myocardial infarction. In the case of symptoms of electrolyte disturbances or in an at-risk patient, laboratory evaluation of electrolytes and renal function must be considered before and after the regimen. As these are low volume hyperosmotic formulations, attention must be paid to encourage the intake of additional liquids to prevent dehydration and electrolyte imbalance.

Even though specific or statistically significantly different adverse events have not been reported in the bisacodyl arms of the aforementioned RCTs, cases of ischemic colitis have been reported following the intake of $>5 \mathrm{mg}$ bisacodyl [113115].

\section{Magnesium citrate with sodium picosulfate (MCSP) ( Table 1, Table 9s)}

Efficacy

Magnesium citrate with sodium picosulfate was compared with PEG and with OSP in two meta-analyses $[116,117]$, including 6 and 13 studies, respectively. In the study by Tan \& Tjandra [116], MCSP provided satisfactory colon cleansing in a similar proportion of patients compared with PEG, with less frequent adverse events. However OSP produced better colon cleansing than MCSP. In the study by Lieshout et al. [117], which included only RCTs in which colon cleansing was rated according to a validated scale, MCSP provided a slightly better quality of bowel cleansing compared with PEG (RR 1.06, 95\%Cl 1.02-1.11); this was lost however when MCSP was compared with 4L PEG only. Moreover, MCSP was better tolerated than PEG, with a higher capability of completing the preparation.

In the most up-to-date meta-analysis [118], including 25 RCTs comparing MCSP with PEG (but with different regimens), no difference was found in colon cleansing, polyp detection rate, and ADR. However adverse events were less frequent in the MCSP group (RR 0.78, 95\%Cl 0.66-0.93; i.e. nausea, vomiting, bloating, but not dizziness), and a higher proportion of patients were likely to complete the MCSP regimen (RR 1.08, $95 \% \mathrm{Cl} 1.04-1.13$ ) and willing to repeat the same regimen (RR $1.44,95 \% \mathrm{Cl}, 1.25-1.67)$.

Since the most up-to-date meta-analysis, four RCTs [94 - 97] have been published that included comparisons between splitdose MCSP vs. split-dose 2 L PEG plus ascorbate (with/without $10 \mathrm{mg}$ bisacodyl); these demonstrated overall high rates of adequate preparation without significant differences between the two regimens. One recent RCT [119] compared 4L PEG vs. MCSP in a primary screening setting, including 13497 patients. Adequate bowel preparation was more frequent in the PEG than in the MCSP group $(86.4 \%$ vs. $79.0 \%$; $P<0.001)$. However, a split regimen was not systematically recommended for either product. 
Safety

Because of hyperosmolarity and magnesium content, solutions containing MCSP are contraindicated in patients with congestive heart disease, hypermagnesemia, rhabdomyolisis, gastrointestinal ulcerations, and severe impairment of renal function, which can lead to magnesium accumulation. In a retrospective population-based study, using administrative data and enrolling >65-year-old patients, compared with PEG, MCSP was associated with an increased risk of hospital admission due to hyponatremia [120]. In a post hoc analysis of two RCTs investigating MCSP regimens (excluding patients with basal renal insufficiency), $10 \%$ of patients had slightly above normal magnesium levels, but this produced no clinically significant effect on monitored cardiac conduction, including in those patients with mild-to-moderate renal impairment [121]. There have been reports of acute gastric and esophageal injury caused by undissolved or poorly dissolved MCSP powder [122].

\section{Oral sulfate solution (OSS) (trisulfate; $>$ Table 1 )}

\section{Efficacy}

Recently, a formulation of magnesium sulfate, sodium sulfate, and potassium sulfate (also called oral sulfate solution [OSS] or trisulfate) has become available in Europe.

This preparation was compared with $4 \mathrm{~L}$ PEG in three RCTs [123-125]. Overall, these trials showed the noninferiority of split OSS versus split high volume PEG in terms of efficacy, a high OSS safety, and better tolerability. In addition, three RCTs compared OSS with 2 L PEG plus ascorbate and showed similarly high efficacy when both regimens were used in split or sameday regimens [126-128].

OSS has also been compared with MCSP in one RCT [129], using the two products in split-dose fashion, and demonstrated better cleansing success in the OSS group.

\section{Safety}

OSS is contraindicated in patients with congestive heart disease, ascites, and severe renal insufficiency (glomerular filtration rate $<30 \mathrm{~mL} / \mathrm{min}$ ). Data are scarce regarding OSS in the setting of renal insufficiency and liver failure. Clinically significant electrolyte disturbances and kidney injury or significant creatinine elevation have not been reported to date [130]. However real-life clinical experience with these solutions is limited and prudence is mandatory. Because of the potential risk of hydroelectrolytic disturbances, laboratory evaluation of electrolytes and renal function may be appropriate before and after the procedure in at-risk patients. Adequate hydration must be encouraged in all patients.

These solutions may also cause transient elevation of uric acid levels, which must be considered in patients affected with hyperuricemia or gout.

\section{Laxatives in elderly people}

There is insufficient evidence to recommend a specific product for elderly people. Osmotically balanced PEG solutions are theoretically the safest, and are preferred in these patients [153]. However high volume products are thought to be particularly poorly tolerated in elderly patients. Even if compliance may be increased with specific measures, the most relevant being the adoption of a split-dose regimen, future research must focus on the safety profile of low volume regimens in the elderly population.

Two RCTs specifically enrolled elderly patients. In one study [60] comparing 2L PEG ascorbate with 4L PEG and enrolling more than 200 patients aged $>65$ years with normal renal function and electrolytes, no increases in adverse events were found (but no laboratory evaluation was done after the regimen), along with comparable cleansing efficacy and higher willingness to repeat the regimen. One RCT [125] randomized almost 200 patients, aged between 65 and 75 and without systemic co-morbidities, to receive OSS or $4 \mathrm{~L}$ PEG both in a split-dose fashion. No differences in frequency of acute kidney injury or significant electrolyte changes were found, along with very high and not different cleansing success between the two groups and significantly higher willingness to repeat the OSS regimen.

RCTs of 1 L PEG ascorbate against OSS [103], MCSP [102], and 2 L PEG ascorbate [104] included a proportion of patients aged between 65-85 years without systemic co-morbidities, but safety outcomes were not specifically reported for these subgroups.

\section{At-risk patients and laxatives}

Even if all cleansing regimens are associated with the risk of dehydration and potential electrolyte imbalances (even caused only by vomiting), hyperosmotic preparations may further increase these risks in at-risk populations, such as patients with chronic renal insufficiency, congestive heart failure, or liver failure with ascites. Although the majority of RCTs exclude such patients, PEG solutions with osmotically balanced electrolytes are often selected, on account of their safety profiles, for patients in these categories [154].

Only retrospective cohorts have found relative safety of PEG in patients with impaired renal function compared to other formulations (e.g. vs. OSP [155]). In one retrospective cohort, patients with glomerular filtration rate $<60 \mathrm{~mL} / \mathrm{min}$ ingested either 4 L PEG or 2 L PEG ascorbate solutions [156]. No statistically significant change in electrolytes or blood urea nitrogen or increase in creatinine was found after intake of either preparation. Comparing the regimens, a transient $>30 \%$ increase in creatinine levels was found in $7.5 \%$ of $4 \mathrm{~L}$ PEG patients and in $11.5 \%$ of 2 L PEG plus ascorbate patients; this was not statistically significantly different [156].

Patients with creatinine clearance $>30 \mathrm{~mL} / \mathrm{min}$ have generally been included in RCTs evaluating PEG plus ascorbate solutions. Further data are needed to recommend a specific regimen in this setting. 


\section{Oral sodium phosphate (OSP)}

\section{RECOMMENDATION}

ESGE recommends against the routine use of oral sodium phosphate for bowel preparation.

Strong recommendation, low quality evidence.

Safety

The most feared adverse event following oral sodium phosphate (OSP) intake is kidney injury. The largest report of kidney injury (21 patients) described the development of acute renal failure within a few weeks after colonoscopy; this modestly improved over time and required renal replacement therapy in four of the patients [131]. A meta-analysis of 7 controlled studies (12 168 patients) that compared the effect of OSP vs. another bowel preparation on kidney function found no statistically significant association between OSP and kidney injury [132]. However, these studies were usually not powered to detect rare serious complications and their tight control of inclusion criteria tended to exclude individuals at risk for complication development. Moreover, between January 2006 and December 2007, 171 cases of renal failure were reported to the United States Food and Drug Administration (FDA) following the use of OSP and 10 following the use of PEG [131]. A retrospective, population-based national analysis in Iceland estimated that the risk of biopsy-proven acute phosphate nephropathy is approximately 1 per 1000 OSP doses sold [131]. Another severe complication of OSP for bowel preparation consists of acute disruption of electrolyte homeostasis, including hyperphosphatemia, hypocalcemia, hypokalemia, and hyperor hyponatremia. The spectrum of clinical presentation varies from mild symptoms related to hypocalcemia to death [131].

Generally accepted contraindications specific to OSP for bowel preparation include the following as absolute contraindications: pregnancy, age $<18$ years, stage $3-5$ chronic kidney disease (glomerular filtration rate $<60 \mathrm{~mL} / \mathrm{min} / 1.73 \mathrm{~m}^{2}$ ), inability to maintain adequate fluid intake, pre-existing electrolyte disturbances, ascites, symptomatic congestive heart failure, and recent (within <6 months) symptomatic ischemic heart disease (unstable angina or myocardial infarction). Relative contraindications include active inflammatory bowel disease, parathyroidectomy, and delayed bowel transit [133-137]. In addition, recognized risk factors for acute phosphate nephropathy following the use of OSP include age $>55$ years, hypovolemia, baseline kidney disease, bowel obstruction, or active colitis, as well as intake of drugs that affect renal perfusion or function such as diuretics, angiotensin-converting enzyme (ACE) inhibitors, angiotensin receptor blockers and, possibly, nonsteroidal anti-inflammatory drugs [133-137].

Care should be taken in individuals with presumably normal renal function because unrecognized chronic kidney disease may affect a large proportion of older individuals (up to $23 \%$ $36 \%$ of people aged 65 years or older) $[138,139]$.

Strategies recommended to prevent acute phosphate nephropathy include: avoidance of OSP in high risk patients; screen- ing for unrecognized chronic kidney disease and electrolyte imbalances; avoiding dehydration before, during, and after OSP administration; minimizing the dose of OSP; and maintaining a minimum of 12 hours between the administration of the two OSP doses [140]. It is the prescribers' responsibility to ensure that the patient understands the importance of maintaining an adequate fluid intake [134]. Renal function should be checked as close to the colonoscopy appointment as practically possible, but in any case within 3 months.

\section{Efficacy (Table 10s)}

Overall, seven meta-analyses, published over an 18-year period (1998 - 2016), have compared oral sodium phosphate with PEG [116, $141-146]$. In the latest meta-analysis including only RCTs comparing OSP and PEG [146], the two regimens demonstrated no difference in the rate of adequate preparation (7 studies, 1128 patients for efficacy assessment), but better scores for OSP when only studies using the Ottawa Bowel Preparation scale were considered. With the OSP regimen, compliance was higher as well as acceptability, with better taste and with less nausea, vomiting, and abdominal pain, and with no statistically significant difference in post-procedural electrolyte imbalance and creatinine levels between the two regimens.

Since the latest meta-analyses, one RCT [147] has been published that compares OSP tablets vs. 4L PEG, both prescribed in split-dose fashion in a selected population without contraindications and severe co-morbidities. The trial showed no difference in colon cleansing efficacy, in polyp detection rate, or in the rate of any adverse events; compliance to the regimen was slightly in favor of OSP tablets, and ingestion was considered significantly easier in that group. Thus, if OSP is used, $90 \mathrm{~mL}$ solution or 32 tablets each containing $1.5 \mathrm{~g}$ sodium phosphate, both in a split-dose regimen, is to be preferred [148-152].

\section{Specific categories of patients}

\section{Patients with constipation}

\section{RECOMMENDATION}

ESGE does not suggest any specific bowel preparation in patients with constipation.

Weak recommendation, low quality evidence.

Chronic constipation has been identified as one of the risk factors for inadequate bowel preparation. Despite the low quality of the evidence, additional bowel purgatives are often considered in patients with chronic constipation who are about to undergo colonoscopy. Since 2013, only five studies have specifically addressed special regimens for constipated patients. However, these few studies are heterogeneous, comparing different bowel preparations, volumes, timings, and adjunctive treatments. There is neither any meta-analysis nor multicenter RCT.

One well-designed RCT in 400 patients with chronic constipation compared 2L PEG plus citrate plus simethicone plus 2day bisacodyl vs. 4L PEG and showed no significant differences 
between groups [157]. Another RCT that included constipated and nonconstipated patients [158] compared four different regimens: OSP vs. OSP plus bisacodyl vs. PEG $4 \mathrm{~L}$ vs. PEG $2 \mathrm{~L}$ plus bisacodyl. The authors reported no statistically significant differences between groups, but when analyzing only constipated patients $(n=65)$, they found that $45 \mathrm{~mL}$ OSP plus $20 \mathrm{mg}$ bisacodyl was significantly superior to the 4-L PEG preparation ( $95 \%$ of patients had satisfactory colon cleansing vs. $66 \%$, respectively; $P=0.03$ ). One nonrandomized study including 372 patients, of whom 65 had constipation, compared 4 L PEG vs. $2 \mathrm{~L}$ PEG plus ascorbate, both in split dose [159]. Based on the Aronchick scale for quality of bowel preparation, the authors did not find statistically significant differences between groups, either in constipated or nonconstipated patients. However, several methodological issues were not clarified. Another nonrandomized Turkish study [160] in 227 patients with constipation (constipation not clearly defined) evaluated the addition of a 200-mL enema to standard preparation with sennoside. They compared three groups: enema before preparation, enema after preparation, and standard preparation (no enema). They did not find overall differences between groups. However, in constipated women, enema before preparation was superior to the other regimens.

In conclusion, evidence is still lacking that would allow recommendation of a special regimen or supplemental treatment for bowel preparation in patients with chronic constipation. Low volume PEG and OSP seem to be better tolerated than $4 \mathrm{~L}$ PEG with no differences regarding efficacy. Despite good results regarding OSP preparations in terms of tolerance, compliance, efficacy, and safety profile in one study, these results are irrelevant in our setting given that the use of OSP is not recommended by current guidelines because of its safety profile [14, 161]. There is no additional evidence to recommend using bisacodyl or enemas as complementary measures in bowel preparation. In special cases, such as cystic fibrosis, more intensive regimens have been suggested [162], but additional evidence is needed.

\section{Patients with inflammatory bowel disease (IBD)}

RECOMMENDATION

ESGE recommends high volume or low volume PEG-based bowel preparation in patients with inflammatory bowel disease (IBD).

Strong recommendation, high quality evidence.

Colon cleansing in inflammatory bowel diseases is critically important both for disease assessment and detection of dysplasia. Recently the promotion of chromoendoscopy in international guidelines has made high quality bowel preparation even more crucial [163]. Patients with IBD bear a heavy burden from colonoscopy for disease assessment and surveillance [164]. One in eight patients may experience a disease flare in the weeks following colonoscopy that may relate to the bowel preparation [165]. In an RCT of patients without colitis, sodium phosphate- or sodium picosulfate-based preparations resulted in a 10-fold increase in mucosal inflammation compared to PEG-based bowel preparation [166]. An observational study of 730 patients noted a $3.3 \%$ rate of erosions or other inflammatory lesions in patients without IBD or without current nonsteroidal anti-inflammatory drug (NSAID) use, that was related to sodium phosphate-based bowel preparation [167].

Limited comparative data are available for bowel preparation efficacy and tolerability in colitis. A recent 2017 meta-analysis identified four fully published comparative studies [168]; no more studies were identified after further searches. One study from the 1980s compared the use of bowel preparation regimens that would not be acceptable in contemporary practice (castor oil vs. high dose senna) [169], and one examined the use of addition of simethicone to PEG-based preparation to reduce bubbling [170]. Two further studies looked at high volume vs. low volume PEG plus adjuvant (ascorbic acid or bisacodyl) preparation $[171,172]$. Combining the latter two studies, which compared low volume PEG $(\leq 2 \mathrm{~L})$ plus adjuvant vs. high volume PEG $(>3 \mathrm{~L})$, no significant difference in bowel cleansing was observed (OR 1.19, $0.52-2.71$ ), though low volume regimes appeared more acceptable to patients (OR for willingness to repeat $5.11,1.31-20.00)$. In an analysis restricted to split-dose high volume PEG vs. split-dose low volume PEG plus adjuvant, there was no difference in preparation quality (OR 0.84, 0.37-1.92). A Japanese RCT, presented as an abstract, that compared low volume PEG plus ascorbic acid vs. large volume PEG alone in patients with ulcerative colitis and Crohn's disease, found similar results in terms of similar or better cleansing with PEG plus adjuvant, and better patient acceptability (author contacted for full results) [173]. Only low volume 2 L PEG-based bowel preparations have been validated in this setting. Data for very low volume $(<2 \mathrm{~L})$ PEG-based bowel preparation with adjuvants are awaited.

Current consensus guidelines recommend chromoendoscopy with targeted biopsies for IBD surveillance [161]. No study has yet focused on which preparation regimes are optimal for chromoendoscopy; however a recent case series noted that having a clear liquid diet for 24 hours pre-procedure led to a higher probability that preparation would be good enough to allow chromoendoscopy (OR 0.11, 95\%Cl $0.01-0.85 ; P<.034$ ) [174].

\section{Pregnant/lactating patients}

\section{RECOMMENDATION}

ESGE found insufficient evidence to determine for or against the use of specific regimens in pregnant/breastfeeding women. However, if colonoscopy is strongly indicated, PEG regimens may be considered, with tapwater enemas preferred for sigmoidoscopy.

Insufficient evidence to determine net benefits or risks.

Colonoscopy appears feasible and relatively safe in pregnancy when strongly indicated [175]. The use of PEG in pregnancy has not been extensively studied and it is unknown whether it can cause fetal harm; when used for treating constipation dur- 
ing pregnancy, it is considered relatively safe. Because full colonoscopy is rarely indicated during pregnancy, tapwater enemas are recommended as bowel preparation for sigmoidoscopy.

No reported series allows any evaluation of the role of bowel preparation during lactation. If bowel preparation is strictly recommended, interrupting breastfeeding during and after bowel preparation may be an option.

\section{Acute lower gastrointestinal bleeding (LGIB)}

\section{RECOMMENDATION}

ESGE recommends PEG regimens for bowel preparation if urgent colonoscopy is scheduled for lower gastrointestinal bleeding (LGIB).

Strong recommendation, moderate quality evidence.

Preparation of the colon in the setting of acute lower GI bleeding facilitates endoscopic visualization, diagnosis, and treatment, and may reduce the risk of bowel perforation. Preparation for colonoscopy should include $4-6 \mathrm{~L}$ of a PEG solution or the equivalent, administered over 3-4 hours until the rectal effluent is clear [176-178]. The use of lower volume or alternative colon preparation solutions in the setting of LGIB has not been specifically addressed, but preliminary data seem encouraging [179].

Many patients with acute LGIB are unable to tolerate rapid colon preparation and thus a nasogastric tube can be placed to facilitate this process as long as the risk of aspiration is low. Aspiration precautions should be used particularly in older and debilitated patients. In addition, administration of a prokinetic/ antiemetic agent immediately prior to initiating the colon preparation may reduce nausea and facilitate gastric emptying. Unprepped sigmoidoscopy/colonoscopy in the setting of acute LGIB is not recommended since cecal intubation rates and diagnostic yields are low, and poor visualization may increase the risk of perforation $[176,177]$.

\section{Inadequate bowel preparation: manage- ment, inpatients, and risk factors}

\section{Management of inadequate bowel preparation}

\section{RECOMMENDATION}

ESGE recommends early repetition of colonoscopy within 1 year in the case of inadequate bowel preparation, unless clinically contraindicated.

Strong recommendation, moderate level of evidence.

Same-day or next-day colonoscopy after additional preparation - with either laxative or enema - may be suggested. The next regimen of bowel preparation should be individualized according to the possible reasons for failure. Weak recommendation, very low level of evidence.
Possible regimens for repeated colonoscopy

As already reported in the Introduction, patients with an inadequate cleansing must repeat the colonoscopy because of a high risk of clinically relevant lesions having been missed. The evidence on the efficacy of a next-day or same-day colonoscopy, after additional bowel preparation, compared with a later colonoscopy is limited and conflicting. In a single-center series of 235 patients with inadequate preparation, next-day colonoscopy vs. non-next-day rescheduled colonoscopy was associated with a reduced risk of secondary failure (OR $0.31,95 \% \mathrm{Cl}$ $0.1-0.92$ ) [180]. This was not confirmed in a larger single-center series of 397 patients with inadequate procedure as recurrent failure was observed in $30 \%$ of the next-day group and $23.5 \%$ of the non-next-day group $(P=0.48)$ [181]. However, in a retrospective study on 3047 procedures with inadequate cleansing, patients advised to have next-day colonoscopy were more likely to adhere to the repeat colonoscopy recommendation [182].

In a single-center prospective nonrandomized study, 87 patients with inadequate preparation after an initial $4 \mathrm{~L}$ PEG received either an additional $2 \mathrm{~L}$ PEG on the same day or a $4 \mathrm{~L}$ PEG plus bisacodyl 1 week later after 3 days of a low residue diet, with no difference found between the two regimens [183]. In an observational study, 60 patients with inadequate preparation received a same-day repeat colonoscopy after receiving an additional laxative of $250 \mathrm{~mL}$ of senna alkaloids with $1.5 \mathrm{~L}$ of water [184]; the repeat colonoscopy reached the cecum in $83 \%$ of patients.

A recent randomized trial showed the superiority of a high volume PEG-based regimen over a low volume PEG when associated with an intensive regimen of preparation [185].

\section{Direct enema or irrigation}

Direct administration of laxative enemas through the colonoscope into the right colon via the biopsy channel $(133 \mathrm{~mL} / 19 \mathrm{~g}$ phosphate enema plus $37 \mathrm{~mL} / 10 \mathrm{mg}$ bisacodyl enema, 10 patients; two $37 \mathrm{~mL} / 10 \mathrm{mg}$ bisacodyl enemas, 11 patients) was reported to be effective in 21 patients with inadequate preparation after low volume PEG and bisacodyl preparation [186]. In a similar study, 26 patients with inadequate preparation after low volume PEG received $500 \mathrm{~mL}$ PEG into the right colon via the coIonoscope biopsy channel. Overall, preparation was successful in 25 patients [187].

On the other hand, a randomized trial compared $1 \mathrm{~L}$ PEG enema administered through the colonoscope to the additional oral ingestion of 2 L PEG in 125 patients with inadequate preparation. An appropriate preparation was obtained in 35 out of $66(53 \%)$ in the enema group vs. 53 out of 67 (81\%) in the oral group, with respective Boston Bowel Preparation Scale scores of 6.3 vs. $7.4(P<0.001)$ [188].

In a single-center study, 42 patients with inadequate preparation were randomized to receive either pump irrigation with a $650 \mathrm{~mL} / \mathrm{min}$ flow rate (Jetprep; Herzliya, Israel) or syringe irrigation with $30-50-\mathrm{mL}$ aliquots. Pump irrigation was superior in improving per-procedure preparation with a significant difference in the right colon [189]. 


\section{Other approaches}

Surveys showed that additional ingestion of the same or a different preparation, additional instillation through the colonoscope, and additional enema are useful, as are rescheduled subsequent colonoscopy with the same or different preparation, or the same preparation but with better observance of diet [190193].

Careful assessment of the primary reason for failure of the previous preparation, such as vomiting, poor adherence, and risk factors for inadequate cleansing, is recommended before prescribing a new regimen.

\section{Bowel preparation in inpatients}

\section{RECOMMENDATION}

ESGE recommends specific verbal or written instructions to patients and to clinic staff caring for hospitalized patients, to improve the quality of bowel preparation.

Strong recommendation, moderate quality evidence.

One recent systematic review and meta-analysis [194] summarized the evidence from eight RCTs and nine observational cohort studies (Table 11s). In this systematic review, included studies were arbitrarily classified according to the intervention used for improving bowel cleanliness as: (a) education of patients and/or personnel regarding bowel preparation; (b) modification of preparation regimen; and (c) other interventions. Colon cleansing that was adequate (or an equivalent measure calculated from the available data) was achieved in 67\% (95\% $\mathrm{Cl}[60-75] \%)$ of patients overall; in $77 \%(62-91) \%$ of the intervention group in the studies assessing the impact of educational interventions vs. $50 \%(32-68) \%$ of the controls; in $71 \%$ (60$81) \%$ of the participants with various preparation regimens; and in $55 \%(22-87) \%$ in the single study examining the administration of bowel preparation through esophagogastroduodenoscopy. The heterogeneity of the various cathartics used and the variation in timing of their administration, and the existence of only a single study in the third intervention group precluded meta-analysis of study results for intervention categories (b) and (c).

Regarding the effect of specific educational intervention, patients in the intervention arms received either brief counselling and written instructions or an educational booklet [195, 196], while in three studies [197-199] leaflets, lectures, and/ or presentations were used to educate personnel involved in patients' preparation. Finally, in one study [200], both personnel and patients were educated. Among these studies the OR $(95 \% \mathrm{Cl})$ of achieving adequate colon cleansing was 3.49 $(1.67-7.28)$ in the intervention group compared to the standard practice group. Inconsistences in the reporting of ADR, adverse events, tolerance, and willingness of patients to repeat the preparation preclude conclusions on the value of the interventions for these outcomes.

There is evidence that the rate of inadequate bowel preparation in inpatients undergoing colonoscopy is high, although several interventions have been implemented to address the problem. There is moderate evidence that educational interventions provided to patients and health care personnel may improve colon cleansing.

\section{Risk factors for inadequate bowel cleansing}

\section{RECOMMENDATION}

ESGE found insufficient data to recommend the use of specific predictive models for inadequate bowel preparation in clinical practice.

Inadequate colon preparation has been reported in up to $18 \%-35 \%$ of patients undergoing colonoscopy [201,202]. Overall, 5 RCTs, 20 prospective and 12 retrospective observational studies, as well one case-control and one study of unknown design attempted to identify predictors of preparation failure (Table 12s) using multivariate analysis. Moreover, two recent meta-analyses including 67 and 24 studies with more than 75000 and almost 50000 participants, respectively, evaluated independent risk factors identified in the literature up to 2016 [201,202]. The authors acknowledged the limitations of their analyses because of the high heterogeneity for all outcomes and because of the mix of RCTs and various types of noninterventional studies. Patients' baseline characteristics (increasing age and male gender), clinical conditions (constipation, diabetes mellitus, hypertension, cirrhosis, stroke, and dementia), and medication use (narcotics and tricyclic antidepressants) were identified as predictors of colonoscopy preparation failure in both meta-analyses. On the other hand, both meta-analyses failed to identify previous abdominal surgery as a predictor, while there were inconsistent results regarding body mass index (BMI) and history of colon preparation failure (Appendix 4s).

Identification of risk factors for poor bowel cleansing would have the potential benefit of selecting patients who need more intensive bowel preparation. Thus, three models have been developed so far using these factors to correctly predict adequate colon cleansing [203-205]. Hassan et al. built their model on patient-related risk factors identified in a multicenter prospective study of 2811 consecutive patients who underwent colonoscopy. The model was established in the exploratory group (randomly half of the included population) and validated in the rest of the participants; the area under the curve of the logistic regression model for predicting adequate bowel preparation was 0.63 [203]. A total of 1331 colonoscopies were included in the development cohort of a Dutch study that identified American Society of Anesthesiologists (ASA) score $\geq 3$, use of tricyclic antidepressants or opioids, diabetes, constipation, previous abdominal and/or pelvic surgery, history of inadequate bowel preparation, and hospitalization as independent predictors for inadequate bowel preparation. These factors were included in the prediction model with a discriminative ability indicated by an area under the curve of 0.77 in the validation cohort [205]. Finally, another model was developed using data from 667 consecutive Spanish outpatients. Antidepressant use, co-morbidity, constipation, and abdominal/pelvic surgery were included in 
the model as independent predictors for inadequate cleansing. The model showed an area under the curve of 0.70 in a validation cohort that included 409 individuals [204]. So far, none of these predictive models have been tested in other than their validation cohort populations, and no study has attempted to apply a different regimen to patients presenting with risk factors for inadequate colon cleanliness.

There is moderate quality evidence that patients' epidemiological and clinical characteristics may predict colonoscopy preparation failure. However, no predictive model has been applied in clinical practice, so far.

\section{Disclaimers}

The legal disclaimer for ESGE Guidelines [16] applies to this Guideline.

Prof. James East was funded by the National Institute for Health Research (NIHR) Oxford Biomedical Research Centre (BRC). The views expressed are those of the author and not necessarily those of the NHS, the NIHR or the UK Department of Health.

\section{Acknowledgment}

The authors are grateful to Dr. Miguel Muños-Navas, Clínica Universitaria de Navarra, Spain, for his review of this Guideline.

\section{Competing interests}

R. Benamouzig has provided consultancy to Alfasigma. R. Bisschops has received speaker's fees from Norgine (1 January 2017 to present); he is Co-Editor of Endoscopy. E. Dekker is Co-Editor of Endoscopy. M. Dinis-Ribeiro is Co-Editor-in-Chief of Endoscopy. J. East received a speaker fee from Falk (January 2018); his department received support from Boston Scientific (March 2018 to March 2019). I. Gralnek declares consultancy, MAB, and share ownership in Motus GI (2014 to present). C. Hassan provides consultancy to Norgine; his department receives support from Alfasigma. $R$. Jover has received travel grants from Norgine (2015 to 2019); he has provided advisory services to Norgine (2015 to 2019), Alfasigma (2017 to 2018), Gl Supply (2018 to 2019), and CPP Pharmaceuticals (2019); his department has received research grants from MSD (2010 to 2019). M.F. Kaminski has provided speaking and teaching services to Olympus, Alfasigma, and Norgine (2017 to present) and Fujinon (2018 to present), consultancy to Olympus (2017 to present), and advisory services to Alfasigma (2017 to present). M. Pellisé has received consultancy fees from Norgine Iberia (2012 to 2017, 2019 to present), and speaker's fees from Casen Recordati (2018) and Olympus (2017); her department has been loaned equipment from Fujifilm (2017 to present); she is on the Endoscopy Board. F. Radaelli has received consultancy fees from Norgine (January 2018 to December 2018). C. Spada has received consultancy fees from Norgina and Alfasigma (2016 to 2019). J.E. van Hooft has received lecture fees from Medtronics (2014 to 2015) and Cook Medical (2019), and consultancy fees from Boston Scientific (2014 to 2017); her department has received research grants from Cook Medical (2014 to 2018) and Abbott (2014 to 2017). H. Awadie, M. Bretthauer, J.-M. Dumonceau, M. Ferlitsch, L. Frazzoni, L. Fuccio, C. Mangas-Sanjuan, K. Triantafyllou, and G. Vanella have no competing interests.

\section{References}

[1] Sulz MC, Kröger A, Prakash M et al. Meta-analysis of the effect of bowel preparation on adenoma detection: early adenomas affected stronger than advanced adenomas. PLoS One 2016; 11: e0154149

[2] Clark BT, Rustagi T, Laine L. What level of bowel prep quality requires early repeat colonoscopy: systematic review and meta-analysis of the impact of preparation quality on adenoma detection rate. Am J Gastroenterol 2014; 109: 1714-1723

[3] Clark BT, Protiva P, Nagar A et al. Quantification of adequate bowel preparation for screening or surveillance colonoscopy in men. Gastroenterology 2016; 150: 396 - 405 quiz e14-15

[4] Hsu C-M, Lin W-P, Su M-Y et al. Factors that influence cecal intubation rate during colonoscopy in deeply sedated patients. J Gastroenterol Hepatol 2012; 27: $76-80$

[5] Radaelli F, Meucci G, Sgroi G et al. Technical performance of colonoscopy: the key role of sedation/analgesia and other quality indicators. Am J Gastroenterol 2008; 103: $1122-1130$

[6] Aslinia F, Uradomo L, Steele A et al. Quality assessment of colonoscopic cecal intubation: an analysis of 6 years of continuous practice at a university hospital. Am J Gastroenterol 2006; 101: 721 - 731

[7] Bugajski M, Wieszczy P, Hoff G et al. Modifiable factors associated with patient-reported pain during and after screening colonoscopy. Gut 2018; 67: 1958 - 1964

[8] Johnson MR, Grubber J, Grambow SC et al. Physician non-adherence to colonoscopy interval guidelines in the Veterans Affairs healthcare system. Gastroenterology 2015; 149: 938-951

[9] Anderson JC, Baron JA, Ahnen DJ et al. Factors associated with shorter colonoscopy surveillance intervals for patients with low-risk colorectal adenomas and effects on outcome. Gastroenterology 2017; 152: 1933-1943.e5

[10] Yadlapati R, Johnston ER, Gregory DL et al. Predictors of inadequate inpatient colonoscopy preparation and its association with hospital length of stay and costs. Dig Dis Sci 2015; 60: $3482-3490$

[11] Rex DK, Imperiale TF, Latinovich DR et al. Impact of bowel preparation on efficiency and cost of colonoscopy. Am J Gastroenterol 2002; 97: $1696-1700$

[12] Kingsley J, Karanth S, Revere FL et al. Cost effectiveness of screening colonoscopy depends on adequate bowel preparation rates - a modeling study. PLoS One 2016; 11: e0167452

[13] Kaminski MF, Thomas-Gibson S, Bugajski M et al. Performance measures for lower gastrointestinal endoscopy: a European Society of Gastrointestinal Endoscopy (ESGE) Quality Improvement Initiative. Endoscopy 2017; 49: 378 - 397

[14] Hassan C, Bretthauer M, Kaminski MF et al. Bowel preparation for colonoscopy: European Society of Gastrointestinal Endoscopy (ESGE) guideline. Endoscopy 2013; 45: $142-150$

[15] Atkins D, Best D, Briss PA. et al.; GRADE Working Group. Grading quality of evidence and strength of recommendations. BMJ 2004; 328: 1490

[16] Dumonceau J-M, Hassan C, Riphaus A et al. European Society of Gastrointestinal Endoscopy (ESGE) Guideline Development Policy. Endoscopy 2012; 44: 626-629

[17] Wu K-L, Rayner CK, Chuah S-K et al. Impact of low-residue diet on bowel preparation for colonoscopy. Dis Colon Rectum 2011; 54: $107-112$

[18] Walter J, Francis G, Matro R et al. The impact of diet liberalization on bowel preparation for colonoscopy. Endosc Int Open 2017; 05: E253-E260

[19] Flemming JA, Green J, Melicharkova A et al. Low-residue breakfast during the preparation for colonoscopy using a polyethylene glycol 
electrolyte solution: a randomised non-inferiority trial. BMJ Open Gastroenterol 2015; 2: e000029

[20] Scott SR, Raymond PL, Thompson WO et al. Efficacy and tolerance of sodium phosphates oral solution after diet liberalization. Gastroenterol Nurs 2005; 28: $133-139$

[21] Melicharkova A, Flemming J, Vanner S et al. A low-residue breakfast improves patient tolerance without impacting quality of low-volume colon cleansing prior to colonoscopy: a randomized trial. Am J Gastroenterol 2013; 108: 1551-1555

[22] Butt J, Bunn C, Paul E et al. The White Diet is preferred, better tolerated, and non-inferior to a clear-fluid diet for bowel preparation: A randomized controlled trial. J Gastroenterol Hepatol 2016; 31: 355 363

[23] Jung YS, Seok HS, Park DI et al. A clear liquid diet is not mandatory for polyethylene glycol-based bowel preparation for afternoon coIonoscopy in healthy outpatients. Gut Liver 2013; 7: 681-687

[24] Nguyen DL, Jamal MM, Nguyen ET et al. Low-residue versus clear liquid diet before colonoscopy: a meta-analysis of randomized, controlled trials. Gastrointest Endosc 2016; 83: 499-507.e1

[25] Avalos DJ, Sussman DA, Lara LF et al. Effect of diet liberalization on bowel preparation. South Med J 2017; 110: 399-407

[26] Song G-M, Tian X, Ma L et al. Regime for bowel preparation in patients scheduled to colonoscopy: low-residue diet or clear liquid diet? Evidence from systematic review with power analysis. Medicine (Baltimore) 2016; 95: e2432

[27] Thukral C, Tewani SK, Lake AJ et al. Results of a community-based, randomized study comparing a clear liquid diet with a low-residue diet using a magnesium citrate preparation for screening and surveillance colonoscopies. J Clin Gastroenterol 2019; 53: 34-39

[28] Samarasena JB, Reataza M, Kwak N et al. Single day low residue diet prior to colonoscopy shows improved tolerance and bowel preparation quality over clear liquid diet: interim results from a U.S. multicenter randomized controlled trial. Gastrointest Endosc 2016; 83: AB172

[29] Gimeno-García AZ, de la Barreda HeuserR, Reygosa C et al. Impact of a 1-day versus 3-day low-residue diet on bowel cleansing quality before colonoscopy: a randomized controlled trial. Endoscopy 2019: Epub ahead of print doi:10.1055/a-0864-1942

[30] Seow-En I, Seow-Choen F. A prospective randomized trial on the use of Coca-Cola Zero $₫$ versus water for polyethylene glycol bowel preparation before colonoscopy. Colorectal Dis 2016; 18: 717-723

[31] Altinbas A, Aktas B, Yilmaz B et al. Adding pineapple juice to a polyethylene glycol-based bowel cleansing regime improved the quality of colon cleaning. Ann Nutr Metab 2013; 63: 83-87

[32] Choi HS, Shim CS, Kim GW et al. Orange juice intake reduces patient discomfort and is effective for bowel cleansing with polyethylene glycol during bowel preparation. Dis Colon Rectum 2014; 57: 1220 1227

[33] Ergül B, Filik L, Koçak E et al. Efficacy and safety of gum chewing in adjunct to high-dose senna for bowel cleansing before colonoscopy: A single-blind randomized controlled trial. Saudi J Gastroenterol 2014; 20: 356

[34] Fang J, Wang S-L, Fu H-Y et al. Impact of gum chewing on the quality of bowel preparation for colonoscopy: an endoscopist-blinded, randomized controlled trial. Gastrointest Endosc 2017; 86: 187-191

[35] Lee J, Lee E, Kim Y et al. Effects of gum chewing on abdominal discomfort, nausea, vomiting and intake adherence to polyethylene glycol solution of patients in colonoscopy preparation. J Clin Nurs 2016; 25: $518-525$

[36] Guo X, Yang Z, Zhao L et al. Enhanced instructions improve the quality of bowel preparation for colonoscopy: a meta-analysis of randomized controlled trials. Gastrointest Endosc 2017; 85: 90 - 97. e6
[37] Jeon SC, Kim JH, Kim SJ et al. Effect of sending educational video clips via smartphone mobile messenger on bowel preparation before colonoscopy. Clin Endosc 2019; 52: 53 - 58

[38] Gálvez M, Zarate A, Espino H et al. A short telephone-call reminder improves bowel preparation, quality indicators and patient satisfaction with first colonoscopy. Endosc Int Open 2017; 05: E1172E1178

[39] Walter B, Klare P, Strehle K et al. Improving the quality and acceptance of colonoscopy preparation by reinforced patient education with short message service: results from a randomized, multicenter study (PERICLES-II). Gastrointest Endosc 2019; 89: 506-513

[40] Back SY, Kim HG, Ahn EM et al. Impact of patient audiovisual reeducation via a smartphone on the quality of bowel preparation before colonoscopy: a single-blinded randomized study. Gastrointest Endosc 2018; 87: 789-799.e4

[41] Banerjee R, Chaudhari $\mathrm{H}$, Shah $\mathrm{N}$ et al. Addition of lubiprostone to polyethylene glycol(PEG) enhances the quality \& efficacy of colonoscopy preparation: a randomized, double-blind, placebo controlled trial. BMC Gastroenterology 2016; 16: 133

[42] Sofi AA, Nawras AT, Pai C et al. Lubiprostone plus PEG electrolytes versus placebo plus PEG electrolytes for outpatient colonoscopy preparation: a randomized, double-blind placebo-controlled trial. Am J Ther 2015; 66: 105-110

[43] Grigg E. Lubiprostone used with polyethylene glycol in diabetic patients enhances colonoscopy preparation quality. World J Gastrointest Endosc 2010; 1: 263-267

[44] Kim HJ, Kim TO, Shin BC et al. Efficacy of prokinetics with a split-dose of polyethylene glycol in bowel preparation for morning colonoscopy: a randomized controlled trial. Digestion 2012; 86: 194-200

[45] Tajika M, Niwa Y, Bhatia V et al. Efficacy of mosapride citrate with polyethylene glycol solution for colonoscopy preparation. World ] Gastroenterol 2012; 18: 2517-2525

[46] Corleto VD, Antonelli G, Coluccio C et al. Efficacy of prucalopride in bowel cleansing before colonoscopy: Results of a pilot study. World Gastrointest Endosc 2017; 9: 558-560

[47] Tajika M, Niwa Y, Bhatia V et al. Can mosapride citrate reduce the volume of lavage solution for colonoscopy preparation? World ] Gastroenterol 2013; 19: 727-735

[48] Wu L, Cao Y, Liao C et al. Systematic review and meta-analysis of randomized controlled trials of simethicone for gastrointestinal endoscopic visibility. Scand J Gastroenterol 2011; 46: 227-235

[49] Pan P, Zhao S-B, Li B-H et al. Effect of supplemental simethicone for bowel preparation on adenoma detection during colonoscopy: $\mathrm{A}$ meta-analysis of randomized controlled trials. J Gastroenterol Hepatol 2019; 34: 314-320

[50] Yeh J-H, Hsu M-H, Tseng C-M et al. The benefit of adding oral simethicone in bowel preparation regimen for the detection of colon adenoma: A systematic review and meta-analysis: simethicone and colon adenoma detection. J Gastroenterol Hepatol 2019; 34: 830 836

[51] Beilenhoff U, Biering H, Blum R et al. Reprocessing of flexible endoscopes and endoscopic accessories used in gastrointestinal endoscopy: Position Statement of the European Society of Gastrointestinal Endoscopy (ESGE) and European Society of Gastroenterology Nurses and Associates (ESGENA) - Update 2018. Endoscopy 2018; 50: $1205-1234$

[52] RE: Use of simethiconeand other non-water soluble additives with Olympus flexible endoscopes, June 29, 2018. http://medical.olympusamerica.com/sites/us/files/pdf/Customer-Letter-Use-of-simethicone-and-lubricants.pdf. Accessed December 15, 2018

[53] Lever EL, Walter MH, Condon SC et al. Addition of enemas to oral lavage preparation for colonoscopy is not necessary. Gastrointest Endosc 1992; 38: 369-372 
[54] Gustafsson UO, Segelman J, Ljungqvist O et al. Can nutritional supplements and rectal enema be used as bowel cleansing for colonoscopy? - Results of a randomized controlled pilot study Scand J Gastroenterol 2014; 49: 485-491

[55] Martel M, Barkun AN, Menard C et al. Split-dose preparations are superior to day-before bowel cleansing regimens: a meta-analysis. Gastroenterology 2015; 149: 79-88

[56] Manes G, Repici A, Hassan C. MAGIC-P study group. Randomized controlled trial comparing efficacy and acceptability of split- and standard-dose sodium picosulfate plus magnesium citrate for bowel cleansing prior to colonoscopy. Endoscopy 2014; 46: 662-669

[57] Schultz C, Müller ], Sauter ] et al. Superiority of a split-dose regimen of sodium picosulfate/magnesium citrate (SPMC) in comparison to a prior-day schedule (AM/PM) for colonoscopy preparation. A randomized single-blinded study. J Gastrointest Liver Dis 2016; 25: $295-302$

[58] Kiesslich R, Schubert S, Mross M et al. Efficacy and safety of PICOPREP tailored dosing compared with PICOPREP day-before dosing for colon cleansing: a multi-centric randomised study. Endosc Int Open 2017; 05: E282-E290

[59] Mohamed R, Hilsden R], Dube C et al. Split-dose polyethylene glycol is superior to single dose for colonoscopy preparation: results of a randomized controlled trial. Can J Gastroenterol Hepatol 2016: doi:10.1155/2016/3181459

[60] Jung YS, Lee CK, Eun CS et al. Low-volume polyethylene glycol with ascorbic acid for colonoscopy preparation in elderly patients: a randomized multicenter study. Digestion 2016; 94: 82 -91

[61] Horton N, Garber A, Hasson H et al. Impact of single- vs. split-dose low-volume bowel preparations on bowel movement kinetics, patient inconvenience and polyp detection: a prospective trial. Am J Gastroenterol 2016; 111: 1330 - 1337

[62] Radaelli F, Paggi S, Hassan C et al. Split-dose preparation for colonoscopy increases adenoma detection rate: a randomised controlled trial in an organised screening programme. Gut 2017; 66: 270-277

[63] Pohl J, Halphen M, Kloess HR et al. Impact of the quality of bowel cleansing on the efficacy of colonic cancer screening: a prospective, randomized, blinded study. PLoS One 2015; 10: e0126067

[64] Gurudu SR, Ramirez FC, Harrison ME et al. Increased adenoma detection rate with system-wide implementation of a split-dose preparation for colonoscopy. Gastrointest Endosc 2012; 76: 603-608.e1

[65] Jover R, Zapater P, Polanía E et al. Modifiable endoscopic factors that influence the adenoma detection rate in colorectal cancer screening colonoscopies. Gastrointest Endosc 2013; 77: 381 -389.e1

[66] Radaelli F, Paggi S, Repici A et al. Barriers against split-dose bowel preparation for colonoscopy. Gut 2017; 66: 1428 -1433

[67] Avalos DJ, Castro FJ, Zuckerman M] et al. Bowel preparations administered the morning of colonoscopy provide similar efficacy to a split dose regimen: a meta analysis. J Clin Gastroenterol 2018; 52 : $859-868$

[68] Cheng Y-L, Huang K-W, Liao W-C et al. Same-day versus split-dose bowel preparation before colonoscopy: a meta-analysis. J Clin Gastroenterol 2018; 52: $392-400$

[69] Shah H, Desai D, Samant $\mathrm{H}$ et al. Comparison of split-dosing vs. nonsplit (morning) dosing regimen for assessment of quality of bowel preparation for colonoscopy. World J Gastrointest Endosc 2014; 6: 606-611

[70] Kotwal VS, Attar BM, Carballo MD et al. Morning-only polyethylene glycol is noninferior but less preferred by hospitalized patients as compared with split-dose bowel preparation. J Clin Gastroenterol 2014; 48: 414-418

[71] Chan W-K, Azmi N, Mahadeva S et al. Split-dose vs. same-day reduced-volume polyethylene glycol electrolyte lavage solution for morning colonoscopy. World J Gastroenterol 2014; 20: 14488 14494
[72] Siddiqui AA, Yang K, Spechler S] et al. Duration of the interval between the completion of bowel preparation and the start of colonoscopy predicts bowel-preparation quality. Gastrointest Endosc 2009; 69: 700 - 706

[73] Seo EH, Kim TO, Park MJ et al. Optimal preparation-to-colonoscopy interval in split-dose PEG bowel preparation determines satisfactory bowel preparation quality: an observational prospective study. Gastrointest Endosc 2012; 75: 583 - 590

[74] Bucci C, Rotondano G, Hassan C et al. Optimal bowel cleansing for colonoscopy: split the dose! A series of meta-analyses of controlled studies Gastrointest Endosc 2014; 80: 566 -576.e2

[75] Shaukat A, Malhotra A, Greer $\mathrm{N}$ et al. Systematic review: outcomes by duration of NPO status prior to colonoscopy. Gastroenterol Res Pract 2017: doi:10.1155/2017/3914942

[76] Xue S, Chen H, Cheng C et al. Gastric residual volume after split-dose bowel preparation versus conventional single-dose regimen before anesthetic colonoscopy. BioMed Res Int 2017: doi:10.1155/2017/ 6543014

[77] Huffman M, Unger RZ, Thatikonda C et al. Split-dose bowel preparation for colonoscopy and residual gastric fluid volume: an observational study. Gastrointest Endosc 2010; 72: 516-522

[78] Tandon K, Khalil C, Castro F et al. Safety of large-volume, same-day oral bowel preparations during deep sedation: a prospective observational study. Anesth Analg 2017; 125: 469-476

[79] Alghamry A, Ponnuswamy SK, Agarwal A et al. Split-dose bowel preparation with polyethylene glycol for colonoscopy performed under propofol sedation. Is there an optimal timing? J Dig Dis 2017; 18: $160-168$

[80] Prieto-Frías C, Muñoz-Navas M, Betés MT et al. Split-dose sodium picosulfate-magnesium citrate colonoscopy preparation achieves lower residual gastric volume with higher cleansing effectiveness than a previous-day regimen. Gastrointest Endosc 2016; 83: 566 573

[81] American Society of Anesthesiologists Committee. Practice guidelines for preoperative fasting and the use of pharmacologic agents to reduce the risk of pulmonary aspiration: Application to healthy patients undergoing elective procedures: An updated report by the American Society of Anesthesiologists Task Force on Preoperative Fasting and the Use of Pharmacologic Agents to Reduce the Risk of Pulmonary Aspiration. Anesthesiology 2017; 126: 376-393

[82] Martel M, Barkun AN, Menard C et al. Split-dose preparations are superior to day-before bowel cleansing regimens: a meta-analysis. Gastroenterology 2015; 149: 79-88

[83] Enestvedt BK, Tofani C, Laine LA et al. 4-Liter split-dose polyethylene glycol is superior to other bowel preparations, based on systematic review and meta-analysis. Clin Gastroenterol Hepatol 2012; 10: $1225-1231$

[84] Rutherford CC, Calderwood AH. Update on bowel preparation for colonoscopy. Curr Treat Options Gastroenterol 2018; 16: 165-181

[85] Patel N, Mori A. Bowel preparation. StatPearls [Internet]. Treasure Island (FL): StatPearls Publishing; 2019-. 2018 Dec 18

[86] Xie Q, Chen L, Zhao F et al. A meta-analysis of randomized controlled trials of low-volume polyethylene glycol plus ascorbic acid versus standard-volume polyethylene glycol solution as bowel preparations for colonoscopy. PLoS One 2014; 9: e99092

[87] Corporaal S, Kleibeuker JH, Koornstra JJ. Low-volume PEG plus ascorbic acid versus high-volume PEG as bowel preparation for colonoscopy. Scand J Gastroenterol 2010; 45: 1380 - 1386

[88] Kwon JE, Lee JW, Im JP et al. Comparable efficacy of a 1-L PEG and ascorbic acid solution administered with bisacodyl versus a 2-L PEG and ascorbic acid solution for colonoscopy preparation: a prospective, randomized and investigator-blinded trial. Plos One 2016; 11: e0162051 
[89] Moon CM, Park DII, Choe YG et al. Randomized trial of 2-L polyethylene glycol + ascorbic acid versus 4-L polyethylene glycol as bowel cleansing for colonoscopy in an optimal setting. J Gastroenterol Hepatol 2014; 29: $1223-1228$

[90] Singh H, Turner D, Xue L et al. Risk of developing colorectal cancer following a negative colonoscopy examination: evidence for a 10 year interval between colonoscopies. JAMA 2006; 295: 2366-2373

[91] Baxter NN, Goldwasser MA, Paszat LF et al. Association of colonoscopy and death from colorectal cancer. Ann Intern Med 2009; 150: $1-8$

[92] Rivas JM, Perez A, Hernandez M et al. Efficacy of morning-only 4 liter sulfa free polyethylene glycol vs. 2 liter polyethylene glycol with ascorbic acid for afternoon colonoscopy. World J Gastroenterol 2014; 20: $10620-10627$

[93] Zorzi M, Valiante F, Germanà B et al. Comparison between different colon cleansing products for screening colonoscopy. A noninferiority trial in population-based screening programs in Italy. Endoscopy 2016; 48: $223-231$

[94] Mathus-Vliegen EMH, van der Vliet K, Wignand-van der Storm IJ et al. Split-dose bowel cleansing with picosulphate is safe and better tolerated than 2-I polyethylene glycol solution. Eur J Gastroenterol Hepatol 2018; 30: 709-717

[95] Seo SI, Kang JG, Kim HS et al. Efficacy and tolerability of 2-L polyethylene glycol with ascorbic acid versus sodium picosulfate with magnesium citrate: a randomized controlled trial. Int J Colorectal Dis 2018; 33: $541-548$

[96] Kojecky V, Matous J, Keil R et al. A head-to-head comparison of 4-L polyethylene glycol and low-volume solutions before colonoscopy: which is the best? A multicentre, randomized trial Int J Colorectal Dis 2017; 32: $1763-1766$

[97] Choi H-S, Chung J-W, Lee JW et al. Polyethylene glycol plus ascorbic acid is as effective as sodium picosulfate with magnesium citrate for bowel preparation: A randomized trial. J Dig Dis 2016; 17: 268-273

[98] Haas S, Andersen LM, Sommer T. Randomized controlled trial comparing Moviprep ${ }^{\circledR}$ and Phosphoral ${ }^{\circledR}$ as bowel cleansing agents in patients undergoing colonoscopy. Tech Coloproctol 2014; 18: $929-$ 935

[99] Ell C, Fischbach W, Layer P et al. Randomized, controlled trial of $2 \mathrm{~L}$ polyethylene glycol plus ascorbate components versus sodium phosphate for bowel cleansing prior to colonoscopy for cancer screening. Curr Med Res Opin 2014; 30: 2493-2503

[100] Spada C, Cesaro P, Bazzoli F et al. Evaluation of Clensia ${ }^{\circledR}$, a new lowvolume PEG bowel preparation in colonoscopy: Multicentre randomized controlled trial versus 4 L PEG. Dig Liver Dis 2017; 49: 651 656

[101] Kump P, Hassan C, Spada C et al. Efficacy and safety of a new lowvolume PEG with citrate and simethicone bowel preparation for colonoscopy (Clensia): a multicenter randomized observer-blind clinical trial vs. a low-volume PEG with ascorbic acid (PEG-ASC). Endosc Int Open 2018; 6: E907-E913

[102] Schreiber S, Baumgart D, Drenth J et al. Colon cleansing efficacy and safety with 1 L NER1006 versus sodium picosulfate with magnesium citrate: a randomized phase 3 trial. Endoscopy 2019; 51: 73-84

[103] DeMicco MP, Clayton LB, Pilot J et al. Novel 1 L polyethylene glycolbased bowel preparation NER1006 for overall and right-sided colon cleansing: a randomized controlled phase 3 trial versus trisulfate. Gastrointest Endosc 2018; 87: 677-687.e3

[104] Bisschops R, Manning J, Clayton L et al. Colon cleansing efficacy and safety with 1 L NER 1006 versus 2 L polyethylene glycol + ascorbate: a randomized phase 3 trial. Endoscopy 2019; 51: 60-72

[105] Clark RE, Godfrey JD, Choudhary A et al. Low-volume polyethylene glycol and bisacodyl for bowel preparation prior to colonoscopy: a meta-analysis. Ann Gastroenterol 2013; 26: 319-324
[106] Repici A, Cestari R, Annese V et al. Randomised clinical trial: lowvolume bowel preparation for colonoscopy - a comparison between two different PEG-based formulations. Aliment Pharmacol Ther 2012; 36: $717-724$

[107] Cesaro P, Hassan C, Spada C et al. A new low-volume isosmotic polyethylene glycol solution plus bisacodyl versus split-dose $4 \mathrm{~L}$ polyethylene glycol for bowel cleansing prior to colonoscopy: A randomised controlled trial. Dig Liver Dis 2013; 45: 23-27

[108] Tae CH, Jung S-A, Na S-K et al. The use of low-volume polyethylene glycol containing ascorbic acid versus $2 \mathrm{~L}$ of polyethylene glycol plus bisacodyl as bowel preparation for colonoscopy. Scand J Gastroenterol 2015; 50: 1039-1044

[109] Valiante F, Bellumat A, De Bona M et al. Bisacodyl plus split 2-L polyethylene glycol-citrate-simethicone improves quality of bowel preparation before screening colonoscopy. World J Gastroenterol 2013; 19: 5493 - 5499

[110] Brahmania M, Ou G, Bressler B et al. 2 L versus 4 L of PEG3350 + electrolytes for outpatient colonic preparation: a randomized, controlled trial. Gastrointest Endosc 2014; 79: 408-416.e4

[111] Kang SH, Jeen YT, Lee JH et al. Comparison of a split-dose bowel preparation with 2 liters of polyethylene glycol plus ascorbic acid and 1 liter of polyethylene glycol plus ascorbic acid and bisacodyl before colonoscopy. Gastrointest Endosc 2017; 86: 343 - 348

[112] Mehta JB, Singhal SB, Mehta BC. Ascorbic-acid-induced haemolysis in G-6-PD deficiency. Lancet 1990; 336: 944

[113] Lopez Morra HA, Fine SN, Dickstein G. Colonic ischemia with laxative use in young adults. Am J Gastroenterol 2005; 100: 2134-2136

[114] Baudet J-S, Castro V, Redondo I. Recurrent ischemic colitis induced by colonoscopy bowel lavage. Am J Gastroenterol 2010; 105: 700 701

[115] Ajani S, Hurt RT, Teeters DA et al. Ischaemic colitis associated with oral contraceptive and bisacodyl use. BMJ Case Rep 2012: doi:10.1136/bcr-12-2011-5451

[116] Tan JJY, Tjandra JJ. Which is the optimal bowel preparation for colonoscopy - a meta-analysis. Colorectal Dis 2006; 8: 247- 258

[117] van Lieshout I, Munsterman ID, Eskes AM et al. Systematic review and meta-analysis: Sodium picosulphate with magnesium citrate as bowel preparation for colonoscopy. United European Gastroenterol 2017; 5: $917-943$

[118] Jin Z, Lu Y, Zhou Y et al. Systematic review and meta-analysis: sodium picosulfate/magnesium citrate vs. polyethylene glycol for coIonoscopy preparation. Eur J Clin Pharmacol 2016; 72: 523-532

[119] Pisera M, Franczyk R, Wieszczy P et al. The impact of low- versus standard-volume bowel preparation on participation in primary screening colonoscopy: a randomized health services study. Endoscopy 2019; 51: $227-236$

[120] Weir MA, Fleet JL, Vinden C et al. Hyponatremia and sodium picosulfate bowel preparations in older adults. Am J Gastroenterol 2014 109: $686-694$

[121] Bertiger G, Jones E, Dahdal D et al. Serum magnesium concentrations in patients receiving sodium picosulfate and magnesium citrate bowel preparation: an assessment of renal function and electrocardiographic conduction. Clin Exp Gastroenterol 2015; 8: 215 224

[122] Ze EY, Choi CH, Kim JW. Acute gastric injury caused by undissolved sodium picosulfate/magnesium citrate powder. Clin Endosc 2017; 50: $87-90$

[123] Rex DK, Di Palma JA, Rodriguez R et al. A randomized clinical study comparing reduced-volume oral sulfate solution with standard 4-liter sulfate-free electrolyte lavage solution as preparation for colonoscopy. Gastrointest Endosc 2010; 72: 328 - 336

[124] Yang H-J, Park S-K, Kim JH et al. Randomized trial comparing oral sulfate solution with $4-\mathrm{L}$ polyethylene glycol administered in a split 
dose as preparation for colonoscopy. J Gastroenterol Hepatol 2017; 32: $12-18$

[125] Kwak MS, Cha JM, Yang H-J et al. Safety and efficacy of low-volume preparation in the elderly: oral sulfate solution on the day before and split-dose regimens (SEE SAFE) Study. Gut Liver 2019; 13: 176-182

[126] Di Palma JA, Rodriguez R, McGowan J et al. A randomized clinical study evaluating the safety and efficacy of a new, reduced-volume, oral sulfate colon-cleansing preparation for colonoscopy. Am J Gastroenterol 2009; 104: 2275-2284

[127] Lee HH, Lim C-H, Kim JS et al. Comparison between an oral sulfate solution and a $2 \mathrm{I}$ of polyethylene glycol+ascorbic acid as a split dose bowel preparation for colonoscopy. J Clin Gastroenterol 2018; doi: 10.1097/MCG.0000000000001137

[128] Kim B, Lee SD, Han KS et al. Comparative evaluation of the efficacy of polyethylene glycol with ascorbic acid and an oral sulfate solution in a split method for bowel preparation. Dis Colon Rectum 2017; 60: $426-432$

[129] Rex DK, DiPalma JA, McGowan J et al. A comparison of oral sulfate solution with sodium picosulfate: magnesium citrate in split doses as bowel preparation for colonoscopy. Gastrointest Endosc 2014; 80: $1113-1123$

[130] Moulin B, Ponchon T. A comparative review of use of sulphate and phosphate salts for colonoscopy preparations and their potential for nephrotoxicity. Endosc Int Open 2018; 6: E1206-E1213

[131] Markowitz GS, Stokes MB, Radhakrishnan J et al. Acute phosphate nephropathy following oral sodium phosphate bowel purgative: an underrecognized cause of chronic renal failure. J Am Soc Nephrol 2005; 16: 3389-3396

[132] Brunelli SM. Association between oral sodium phosphate bowel preparations and kidney injury: a systematic review and meta-analysis. Am J Kidney Dis 2009; 53: 448-456

[133] Wexner SD, Beck DE, Baron TH et al. A consensus document on bowel preparation before colonoscopy: prepared by a task force from the American Society of Colon and Rectal Surgeons (ASCRS), the American Society for Gastrointestinal Endoscopy (ASGE), and the Society of American Gastrointestinal and Endoscopic Surgeons (SAGES). Gastrointest Endosc 2006; 63: 894 - 909

[134] Balaban DH. Guidelines for the safe and effective use of sodium phosphate solution for bowel cleansing prior to colonoscopy. Gastroenterol Nurs 2008; 31: $327-334$

[135] Rex DK, Vanner SJ. Colon cleansing before colonoscopy: does oral sodium phosphate solution still make sense? Can J Gastroenterol 2009; 23: $210-214$

[136] Marshall JB, Pineda J], Barthel JS et al. Prospective, randomized tria comparing sodium phosphate solution with polyethylene glycolelectrolyte lavage for colonoscopy preparation. Gastrointest Endosc39: 631-634

[137] Hookey LC, Vanner S. Recognizing the clinical contraindications to the use of oral sodium phosphate for colon cleansing: a case study. Can J Gastroenterol 2004; 18: 455-458

[138] Russmann S, Lamerato L, Marfatia A et al. Risk of impaired renal function after colonoscopy: a cohort study in patients receiving either oral sodium phosphate or polyethylene glycol. Am J Gastroenterol 2007; 102: 2655-2663

[139] Zhang Q-L, Rothenbacher D. Prevalence of chronic kidney disease in population-based studies: systematic review. BMC Public Health 2008; 8: 117

[140] Markowitz GS, Perazella MA. Acute phosphate nephropathy. Kidney Int 2009; 76: 1027 - 1034

[141] Belsey ], Crosta C, Epstein O et al. Meta-analysis: the relative efficacy of oral bowel preparations for colonoscopy 1985-2010. Aliment Pharmacol Ther 2012; 35: 222-237
[142] Juluri R, Eckert G, Imperiale TF. Meta-analysis: randomized controlled trials of 4-L polyethylene glycol and sodium phosphate solution as bowel preparation for colonoscopy. Aliment Pharmacol Ther 2010; 32: $171-181$

[143] Juluri R, Eckert G, Imperiale TF. Polyethylene glycol vs. sodium phosphate for bowel preparation: a treatment arm meta-analysis of randomized controlled trials. BMC Gastroenterol 2011; 11: 38

[144] Hsu CW, Imperiale TF. Meta-analysis and cost comparison of polyethylene glycol lavage versus sodium phosphate for colonoscopy preparation. Gastrointest Endosc 1998; 48: 276-282

[145] Belsey J, Epstein O, Heresbach D. Systematic review: oral bowel preparation for colonoscopy. Aliment Pharmacol Ther 2007; 25: $373-384$

[146] Cheng J, Tao K, Shuai X et al. Sodium phosphate versus polyethylene glycol for colonoscopy bowel preparation: an updated meta-analysis of randomized controlled trials. Surg Endosc 2016; 30: 4033 -4041

[147] Chaussade S, Schmöcker C, Toulemonde P et al. Phosphate tablets or polyethylene glycol for preparation to colonoscopy? A multicentre non-inferiority randomized controlled trial Surg Endosc 2017; 31: $2166-2173$

[148] Frommer D. Cleansing ability and tolerance of three bowel preparations for colonoscopy. Dis Colon Rectum 1997; 40: 100 - 104

[149] Wruble L, Demicco M, Medoff J et al. Residue-free sodium phosphate tablets (OsmoPrep) versus Visicol for colon cleansing: a randomized, investigator-blinded trial. Gastrointest Endosc 2007; 65: 660-670

[150] Rex DK, Schwartz H, Goldstein M et al. Safety and colon-cleansing efficacy of a new residue-free formulation of sodium phosphate tablets. Am J Gastroenterol 2006; 101: 2594 - 2604

[151] Malik P, Balaban DH, Thompson WO et al. Randomized study comparing two regimens of oral sodium phosphates solution versus lowdose polyethylene glycol and bisacodyl. Dig Dis Sci 2009; 54: 833 841

[152] Law W-L, Choi H-K, Chu K-W et al. Bowel preparation for colonoscopy: a randomized controlled trial comparing polyethylene glycol solution, one dose and two doses of oral sodium phosphate solution. Asian J Surg 2004; 27: 120 - 124

[153] Ho SB, Hovsepians R, Gupta S. Optimal bowel cleansing for colonoscopy in the elderly patient. Drugs Aging 2017; 34: $163-172$

[154] Rex DK. Optimal bowel preparation - a practical guide for clinicians. Nat Rev Gastroenterol Hepatol 2014; 11: 419-425

[155] Russmann S, Lamerato L, Motsko SP et al. Risk of further decline in renal function after the use of oral sodium phosphate or polyethylene glycol in patients with a preexisting glomerular filtration rate below 60 mL/min. Am J Gastroenterol 2008; 103: 2707-2716

[156] Lee JM, Keum B, Yoo IK et al. Polyethylene glycol plus ascorbic acid for bowel preparation in chronic kidney disease. Medicine (Baltimore) 2016; 95: e4755

[157] Parente F, Vailati C, Bargiggia S et al. 2-Litre polyethylene glycol-citrate-simethicone plus bisacodyl versus 4-litre polyethylene glycol as preparation for colonoscopy in chronic constipation. Dig Liver Dis 2015; 47: 857-863

[158] Pereyra L, Cimmino D, González MallaC et al. Colonic preparation before colonoscopy in constipated and non-constipated patients: a randomized study. World J Gastroenterol 2013; 19: 5103-5110

[159] Kunz L, Gillespie D. A comparison of bowel preparations for colonoscopy in constipated adults. Gastroenterol Nurs 2017; 40: 364 372

[160] Yıldar M, Yaman I, Başbuğ M et al. A new approach in bowel preparation before colonoscopy in patients with constipation: A prospective, randomized, investigator-blinded trial. Turk J Surg 2017; 33: $29-32$

[161] Mathus-Vliegen E, Pellisé M, Heresbach D et al. Consensus guidelines for the use of bowel preparation prior to colonic diagnostic 
procedures: colonoscopy and small bowel video capsule endoscopy. Curr Med Res Opin 2013; 29: 931 - 945

[162] Hadjiliadis D, Khoruts A, Zauber AG et al. Cystic fibrosis colorectal cancer screening consensus recommendations. Gastroenterology 2018; 154: 736-745.e14

[163] Laine L, Kaltenbach T, Barkun A et al. SCENIC international consensus statement on surveillance and management of dysplasia in inflammatory bowel disease. Gastroenterology 2015; 148: 639-651. e28

[164] Denters M], Schreuder M, Depla ACTM et al. Patients' perception of colonoscopy: patients with inflammatory bowel disease and irritable bowel syndrome experience the largest burden. Eur J Gastroenterol Hepatol 2013; 25: $964-972$

[165] Menees S, Higgins P, Korsnes S et al. Does colonoscopy cause increased ulcerative colitis symptoms? Inflamm Bowel Dis 2007; 13: $12-18$

[166] Lawrance IC, Willert RP, Murray K. Bowel cleansing for colonoscopy: prospective randomized assessment of efficacy and of induced mucosal abnormality with three preparation agents. Endoscopy 2011; 43: $412-418$

[167] Rejchrt S, Bures J, Siroký M et al. A prospective, observational study of colonic mucosal abnormalities associated with orally administered sodium phosphate for colon cleansing before colonoscopy. Gastrointest Endosc 2004; 59: 651 - 654

[168] Restellini S, Kherad O, Bessissow T et al. Systematic review and meta-analysis of colon cleansing preparations in patients with inflammatory bowel disease. World J Gastroenterol 2017; 23: 5994

[169] Gould SR, Williams CB. Castor oil or senna preparation before colonoscopy for inactive chronic ulcerative colitis. Gastrointest Endosc 1982; 28: 6-8

[170] Lazzaroni M, Petrillo M, Desideri S et al. Efficacy and tolerability of polyethylene glycol-electrolyte lavage solution with and without simethicone in the preparation of patients with inflammatory bowel disease for colonoscopy. Aliment Pharmacol Ther 1993; 7: 655-659

[171] Kim ES, Kim KO, Jang BI et al. Crohn's and Colitis Association in Daegu-Gyeongbuk (CCAiD). Comparison of 4-L polyethylene glycol and 2-L polyethylene glycol plus ascorbic acid in patients with inactive ulcerative colitis. Dig Dis Sci 2017; 62: 2489-2497

[172] Manes G, Fontana P, de Nucci G et al. Colon cleansing for colonoscopy in patients with ulcerative colitis: efficacy and acceptability of a 2-L PEG plus bisacodyl versus 4-L PEG. Inflamm Bowel Dis 2015; 21 : $2137-2144$

[173] Kato S, Kani K, Kobayashi T et al. Su1538 The safety and feasibility study of bowel cleaning agents MoviPrep ${ }^{\circledR}$ versus Niflec ${ }^{\circledR}$ for the patients with inflammatory bowel diseases undergoing colonoscopy and balloon enteroscopy: a single center randomized controlled trial. Gastrointest Endosc 2015; 81: AB320

[174] Megna B, Weiss ], Ley D et al. Clear liquid diet before bowel preparation predicts successful chromoendoscopy in patients with inflammatory bowel disease. Gastrointest Endosc 2019; 89: 373-379. e2

[175] Cappell MS, Fox SR, Gorrepati N. Safety and efficacy of colonoscopy during pregnancy: an analysis of pregnancy outcome in 20 patients. J Reprod Med 2010; 55: 115 - 123

[176] Gralnek IM, Neeman Z, Strate LL. Acute lower gastrointestinal bleeding. N Engl J Med 2017; 376: 1054-1063

[177] Strate LL, Gralnek IM. ACG Clinical guideline: Management of patients with acute lower gastrointestinal bleeding. Am J Gastroenterol 2016; 111: 459-474

[178] Pasha SF, Shergill A. et al. ASGE Standards of Practice Committee. The role of endoscopy in the patient with lower GI bleeding. Gastrointest Endosc 2014; 79: 875-885
[179] Pontone S, Palma R, Panetta C et al. Polyethylene glycol-based bowel preparation before colonoscopy for selected inpatients: A pilot study. J Dig Dis 2018; 19: 40-47

[180] Ben-Horin S, Bar-Meir S, Avidan B. The outcome of a second preparation for colonoscopy after preparation failure in the first procedure. Gastrointest Endosc 2009; 69: 626-630

[181] Murphy C], Jewel Samadder N, Cox K et al. Outcomes of next-day versus non-next-day colonoscopy after an initial inadequate bowel preparation. Dig Dis Sci 2016; 61: $46-52$

[182] Chokshi RV, Hovis CE, Colditz GA et al. Physician recommendations and patient adherence after inadequate bowel preparation on screening colonoscopy. Dig Dis Sci 2013; 58: 2151 - 2155

[183] Kim JW, Han JH, Boo S-J et al. Rescue bowel preparation: same day 2 L polyethylene glycol addition, not superior to bisacodyl addition 7 days later. Dig Dis Sci 2014; 59: 2215-2221

[184] Akgul G, Ozgur YeniovaA, Ozsoy Z et al. Effect and tolerability of same-day repeat colonoscopy. J Invest Surg 2018: Oct 31: 1-7 doi:10.1080/08941939.2018.1513611

[185] Gimeno-García AZ, Hernandez G, Aldea A et al. Comparison of two intensive bowel cleansing regimens in patients with previous poor bowel preparation: a randomized controlled study. Am J Gastroenterol 2017; 112: $951-958$

[186] Sohn N, Weinstein MA. Management of the poorly prepared colonoscopy patient: colonoscopic colon enemas as a preparation for colonoscopy. Dis Colon Rectum 2008; 51: $462-466$

[187] Horiuchi A, Nakayama Y, Kajiyama M et al. Colonoscopic enema as rescue for inadequate bowel preparation before colonoscopy: a prospective, observational study. Colorectal Dis 2012; 14: e735 e739

[188] Yang H-J, Park DI, Park S-K et al. A randomized controlled trial comparing colonoscopic enema with additional oral preparation as a salvage for inadequate bowel cleansing before colonoscopy. J Clin Gastroenterol 2018: doi:10.1097/MCG.0000000000001087, Epub ahead of print

[189] Rigaux J, Juriens I, Devière J. A novel system for the improvement of colonic cleansing during colonoscopy. Endoscopy 2012; 44: $703-$ 706

[190] Larsen M, Hills N, Terdiman ]. The impact of the quality of colon preparation on follow-up colonoscopy recommendations. Am J Gastroenterol 2011; 106: 2058-2062

[191] Hillyer GC, Basch CH, Lebwohl B et al. Shortened surveillance intervals following suboptimal bowel preparation for colonoscopy: results of a national survey. Int J Colorectal Dis 2013; 28: 73-81

[192] Seong JH, Yoo JS, Lee KJ et al. Formulation and management of poor bowel preparation: a survey study. Korean J Gastroenterol 2016; 68: 70

[193] Maratt JK, Menees SB, Piper MS et al. Patients are willing to repeat colonoscopy at a short interval when bowel preparation quality is suboptimal. Clin Gastroenterol Hepatol 2018; 16: 776 - 777

[194] Gkolfakis P, Tziatzios G, Papanikolaou IS et al. Strategies to improve hospitalized patients' quality of bowel preparation for colonoscopy: systematic review and meta-analysis. Gastroenterol Res Pract 2019: doi: doi.org/10.1155/2019/5147208

[195] Ergen WF, Pasricha T, Hubbard FJ et al. Providing hospitalized patients with an educational booklet increases the quality of colonoscopy bowel preparation. Clin Gastroenterol Hepatol 2016; 14: 858 864

[196] Rosenfeld G, Krygier D, Enns RA et al. The impact of patient education on the quality of inpatient bowel preparation for colonoscopy. Can J Gastroenterol 2010; 24: 543 - 546

[197] Chorev N, Chadad B, Segal N et al. Preparation for colonoscopy in hospitalized patients. Dig Dis Sci 2007; 52: 835-839 
[198] Lee Y], Kim ES, Park KS et al. Education for ward nurses influences the quality of inpatient's bowel preparation for colonoscopy. Medicine (Baltimore) 2015; 94: e1423

[199] Chambers K, Whiteman K, Stephens K et al. Improving inpatient colonoscopy preparation in a university hospital: an evidence-based practice project. Gastroenterol Nurs 2016; 39: 86 - 94

[200] Shah-Khan SM, Cumberledge J, Reynolds G]. Using the plan-dostudy-act approach to improve inpatient colonoscopy preparation. BMJ Open Qual 2017; 6: e000230

[201] Gandhi K, Tofani C, Sokach C et al. Patient characteristics associated with quality of colonoscopy preparation: a systematic review and meta-analysis. Clin Gastroenterol Hepatol 2018; 16: 357-369.e10
[202] Mahmood S, Farooqui SM, Tajammal R et al. Predictors of inadequate bowel preparation for colonoscopy: a systematic review and meta-analysis. Gastroenterology 2017; 152: S731

[203] Hassan C, Fuccio L, Bruno M et al. A predictive model identifies patients most likely to have inadequate bowel preparation for colonoscopy. Clin Gastroenterol Hepatol 2012; 10: 501 - 506

[204] Gimeno-García A, Baute J, Hernandez G et al. Risk factors for inadequate bowel preparation: a validated predictive score. Endoscopy 2017; 49: $536-543$

[205] Dik VK, Moons LMG, Hüyük M et al. Predicting inadequate bowel preparation for colonoscopy in participants receiving split-dose bowel preparation: development and validation of a prediction score. Gastrointest Endosc 2015; 81: 665-672 